$62.163: 666.94 .0125=60$

\title{
los ensayos de calidad en los laboratorios de fábricas*
}

1. LOS PLIEGOS DE CONDICIONES Y EL PROGRESO INDUSTRIAL.

El cemento portland no es un compuesto químico de propiedades definidas y constantes, sino un producto industrial que suele presentar grandes variaciones, tanto en st composición química, como en sus propiedades físicas y mecánicas.

Amparados con el nombre genérico de "cemento», y aun con la denominación específica de "cemento portland", se han puesto ocasionalmente a la venta productos de dudosa calidad, que han sembrado desconfianzas entre los usuarios y han servido de plataforma para determinadas campañas de descrédito.

Con los llamados "Cuadernos de Encar. gos» o "Pliegos de Condiciones" se ha intentado normalizar la producción, con el loable fin de proteger el crédito de los productos y el interés de los consumidores.

En general, cuando se establecen ciertas condiciones que debe satisfacer un producto, to que en realidad se hace es sancionar por ley to que ya estaba tácitamente esta-

(*) Ponencia presentada en los II Coloquios de Directores y Técnicos de Fábricas de Cemento. 1. T. C. C., marzo 1957 .
D. ALBERTO VIRELLA BLODA de la Compañia Portuguesa de Cementos Blancos (ClBRA).

blecido: En el caso del cemento, unas condiciones normalizadas en 1930 corresponden, ni más ni menos, a los tipos y calidades de cemento que se fabricaban hace veintisiete años.

El progreso industrial de todas las ramas de la producción, observado después de las dos últimas décadas, forzosamente tenía que afectar a la industria cementera, ya sea por la aparición de nuevos modelos de máquinas -principalmente hornos y molinos-o de nuevos tipos de cemento exigidos por los constructores, o sea, también, por la evohución técnica de los procedimientos para el ensayo de materiales.

Como consecuencia del dinamismo del progreso industrial y del estacionamiento de unas Normas que fueron promulgadas en 1930, 1a industria portuguesa habia superado tan ampliamente al antiguo reglamento, que bien puede decirse que las condiciones ya nada condicionaban, y habría sido un grave perjuicio para un fabricante lanzar al mercado un cemento que hubiese satisfecho estrictamente las prescripciones del cuaderno de 1930.

E1 fabricante suele tener un triple objetivo: producir más, mejor y con la máxima economía. Para producir mejor tiene que organizar el «control» de la calidad de sus 
productos, y como punto de partida para los ensayos de verificación de calidad no tiene otro que el proporcionado por las Normas vigentes. Pero si ha llegado un momento en que estas Normas ya se han desactualizado, el control de calidad puede caer en un vago indeterminismo, en virtud del excesivo alejamiento existente entre una característica cualquiera y su especificación de hace veintisiete años.

Entonces surge espontáneamente la necesidad de adoptar nuevas técnicas y métodos de ensayo, principalmente por parte de los laboratorios de fábricas $\mathrm{y}$, como reacción consiguiente, por parte de los laboratorios oficiales aparece la conveniencia de revisar $y$ poner al dia las Normas anticuadas.

En algunos países existe un Organismo de normalización permanente que va revisando $y$, en su caso, propone para modificar todas las cláusulas normativas sujetas a su ámbito. Todos conocemos el funcionamiento de la American Society for Testing Materials $y$, por lo tanto, excusamos elogios para una labor $\tan$ importante como la que en ella se realiza. Las Normas de ensayo para un producto cualquiera van modificándose poco a poco y no se causan trastornos al productor ni al ustsario.

En otros paises, donde la normalización sólo es revisada desptés de plazos muy dilatados, las alteraciones son causa de grandes polémicas. Y está claro que, cuando esto acontece, quieran hacer oír sus voces los laboratorios de ensayos de las fábricas.

\section{MÉtodos DE LOS laboratortos DE FÁBRICA}

El control de la calidad de los cementos producidos no es la función exclusiva de los laboratorios de fábricas. Hay que ensa- yar, además, materins primas, productos semifabricados, combustibles y lubricantes. Y todo ello con urgencia, procurando obtener los resultados a la mayor brevedad posible.

La fábrica labora en trabajo continuo. Para acompañar eficazmente a la producción es necesario detectar y corregir los errores dentro del tiempo mínimo, para reducir en lo posible los efectos de la perturbación. El laboratorio de fábrica suele trabajar "contra el reloj». Por este motivo escoge métodos y procedimientos rápidos, abreviados o expeditivos, sabiendo que sacrifica, a veces, la rigurosa exactitud en aras de la velocidad.

Cuando se adoptan tales métodos, no hay que perder de vista el error probable que con ellos cometemos. E1 abuso sistemático e inmoderado de los métodos expeditivos, puede ser causa de desvíos progresivos que conviene mucho evitar.

En ciertos casos, en los análisis químicos por ejemplo, lo más simple y natural es que efectuemos periódicamente análisis de verificación siguiendo procedimientos rigurosos. En otros casos, se ejerce una especie de «control remoton del trabajo de los laboratorios de fábrica, por medio de ensayos efectuados por otros laboratorios, sea en los laboratorios centrales de las Compañías con varias plantas fabriles, o sea en los laboratorios oficiales del Estado.

Para la apreciación de las divergencias que inevitablemente presentan los resultados obtenidos en uno o en otro laboratorio, toda cautela es poca. No es axiomático que el error esté siempre en un lado y la exactitud en otro.

El laboratorio de fábrica tiene el deber de ser sincero, por lo menos consigo mismo. No sentir preocupación cuando en otro 1a- 
Loratorio muestro cemento 110 cumple una condición que sobreentendemos cumplida, de acuerdo con muestros resultados, puede ser peligroso. Pero el peligro aumentará hasta limites extremos si forzamos el cumplimiento de la condición que 'estaba en entredicho, enviando a un Laboratorio oficial una muestra escogida contra todos los principios de la casualidad y que sabemos, de antemano, que va a dar excelente resultado.

Por caminos tortuosos nos perderemos en las sombras del indeterminismo, y llegará momento én que el laboratorio de fábrica no cumplirá con su función natural $y$, alcanzado este punto, el fabricante ya no sabe lo que produce.

\section{TOMA DE MUESTRAS}

Partiendo del principio de que la seriedad y la honestidad del trabajo de un laboratorio de fábrica debe estár fuera de toda duda, el primer punto que debe ser objeto de una cuidadosa vigilancia es la toma de muestras. Debe evitarse y sancionarse todo intento de falsificación o selección en las operaciones de muestreo. Sobre esto no queremos insistir.

En otro tiempo trabajamos con las llamadas muestras medias. Así, por ejemplo, del cemento ensacado se tomaba una pequeña cantidad de cemento cada diez o cada yeinte sacos. Reunidas las tomas en un recipiente, se mezclaban, formando una muestra representativa de un vagón, que se sometía a determinados ensayos. Mezclando las muestras de vagones correspondientes a un mismo día se formaba una muestra mayor, representativa de las salidas diarias, la cual era sometida a’ ensayos más completos.

Hoy en dia, por to menos nosotros, preferimos otro sistena de tomar muestras, en el cual el azar juega un papel más importante. Un saco de cemento es separado diariamente en un momento cualquiera de las operaciones de ensacado: Este saco se entrega al laboratorio cerrado, y sólo se abre cuando van a efectuarse los ensayos de calidad que normalmente se ejecutan.

Puede ser que el cemento contenido en el saco ensayado sea de una calidad anormalmente superior, pero también es posible que, por causas ignoradas, contenga un cemento de características excepcionalmente deficientes. A fin de cuentas, esta casualidad es la que se dará en la obra. El cemento de baja calidad contenido en un único saco, puede ser empleado en el hormigonado de un punto clave y poner en peligro la totalidad de la construcción.

Por este procedimiento se obtendrán cartas de control con amplia fluctuación de ciertas características y sus puntas mínimas se acercarán, o incluso rebasarán, los límites de confianza y de vigilancia en grado mucho mayor que si operásemos con muestras medias.

A partir de 1952 , en Portugal se comenzó a poner en práctica un vasto plan de «Ensayos Sistemáticos de los Cementos Nacionales), elaborado y dirigido por el (Laboratorio Nacional de Engenharia Civil», con la colaboración técnica y económica de las cinco fábricas de cemento portland existentes en la metrópoli.

El sistema de muestreo usado en este plan fué el antes indicado. El Laboratorio Nacional separaba cada quincena un saco de cemento portland de cada una de las cinco marcas, en los mismos almacenes de Lisboa que abastecen a los consumidores. Del saco separado se tomaban y envasaban varias muestras, cerradas en latas metálicas sol- 
dadas, una de las cuales se enviaba ai laboratorio de la fábrica de donde procedía el cemento, y otra era entregada a las secciones correspondientes del aLaboratorio $\mathrm{Na}$ cional de Engenharia Civil). Una tercera lata se almacenaba para el caso en que fuera conveniente repetir algún ensayọ. Este procedimiento precedió a la puesta en vigor de las actuales Normas de ensayo de cementos y continúa empleándose después de la reciente publicación del nuevo Cuaderno de Encargos, que, abreviadamente, designaremos por N. P. 1956.

\section{ANÁlisis QUímico}

El cCaderno de Encargos para o Fornecimento o Recepção do Cimento "Portland" Normalm, tanto en su antigua versión de 28 de agosto de 1930 , como en su nueva de 22 de noviembre de 1956, no exige el análisis químico completo de los cementos $\mathrm{y}$, por ello, no se especifica un procedimiento que abarque la totalidad de las determinaciones habituales.

Los ensayos de laboratorio en este caso concreto tienen que salirse mucho más allá de los límites de las Normas. Con independencia de los métodos seguidos, no es preciso destacar la importancia que tiene el conocimiento de la composición química de los productos semifabricados, de las materias primas y del cemento acabado.

Entre los métodos analíticos más rigurosos, los propuestos por la A. S. T. M (Método normalizado $C$ 114) merecieron la especial atención de los cementistas portugueses. Con pocas variantes fueron los que adoptó el L. N. E. C. en su Memoria de marzo de 1955 .

En los laboratorios de fábricas, por las exigencias de tiempo antes expirestas, no es posible ceñirse con todo rigor a la norma C 114. La tendencia a ganar tiempo, afecta a las determinaciones analíticas en mayor grado que a otros ensayos.

Sin entrar en la ardua discusión de un tema tan vasto, y resumiendo los puntos sobre los cuales se estableció un mayor grado de acuerdo entre el L. N. E. C. y los cementistas, distinguimos, en primer lugar:

\section{a) Determinaciones principales.}

Son aquellas que constituyen la composición centesimal comúnmente aceptada para el cemento, o sea: pérdida al fuego, sílice, alúmina y óxido férrico, cal, magnesia, anhídrido sulfúrico y materias no dosificadas.

En lugar no menos importante se tienen:

b) Determinaciones separadas.

Aqquellas que no se suelen incluir en la composición centesimal del cemento, particularmente el residuo insoluble y la cal libre.

En segundo plano aparecen:

c) Determinaciones secundarias.

Las que sirven para valorar a todos los restantes componentes del cemento no incluídos en los apartados a) y $b$ ), o sea: humedad, anhídrido carbónico, titanio, fósforo, manganeso, óxido ferroso, sulfuros, alcalis, materia orgámica, etc., etc.

Estas determinaciones secundarias solamente en ciertas eventualidades son efectuadas en los laboratorios de fábrica. Estas eventualidades, cuando se presume que uno de los componentes secundarios tiene gran importancia para una propiedad cualquiera del cemento obtenido, pasan a convertirse en rutinarias y se entra de lleno en un control 
permanente y sistemático. Esto ha sucedido, en casos especiales, con los álcalis, el manganeso, los sulfuros y el fósforo.

Todas estas consideraciones sirven para argumentar el carácter relativo que tienen los resultados del análisis químico más cuidadosamente efectuado. Sin que se pueda dar una explicación concreta del porqué, el caso es que nunca se obtuvieron resultados idénticos cuando fué analizado el mismo material en dos laboratorios diferentes. A los errores personales, se suman diferencias en los métodos operatorios, en los reactivos empleados y en la pureza del agua destilada. La porosidad de los papeles-filtro es muy importante. En los «Ensayos Sistemáticos», entre 1953 y 1955 , para un mismo cemento, se obtuvo:

\begin{tabular}{|c|c|c|}
\hline & Laboratorio I & Laboratorio II \\
\hline Pérdida al fuego . . . . . . . & $2,58 \%$ & $2,43 \%$ \\
\hline $\mathrm{SiO}_{2}+$ insoluble. $\ldots \ldots$ & $23,56 ”$ & $23,88 "$ \\
\hline Alúmina $\left(\mathrm{Al}_{2} \mathrm{O}_{3}\right) \ldots \ldots \ldots$ & 5,01 . & $4.80 n$ \\
\hline Oxido férrico $\left(\mathrm{Fe}_{2} \mathrm{O}_{3}\right) \ldots \ldots$ & 0.98 ; & 0,91 . \\
\hline $\mathrm{Cal}(\mathrm{CaO}) \ldots \ldots \ldots \ldots$ & 65,56 & $65,25 »$ \\
\hline Magnesia $(\mathrm{MgO}), \ldots \ldots \ldots$ & 0,29 ” & $0,64 *$ \\
\hline Anhidrido sulfúrico $\left(\mathrm{SO}_{3}\right)$. & 1,77 & 1,81 \\
\hline No dosificado .......... & $0,25 n$ & 0,28 , \\
\hline Suma..... & $100,00 \%$ & $100,00 \%$ \\
\hline
\end{tabular}

\section{Mó́dulos Químicos}

Las N.P. 1956 no establecen ninguna limitación para los módulos químicos más conocidos del cemento portland. En cambio, en el caso de destinarse el cemento portland a obras stujetas a la acción de aguas salinas se aplican unas "Cláusulas Especiales», aprobadas por Decreto de 20 de febrero de 1932 , en las cuales se limita el valor del módulo hidránlico, que debe quedar comprendido entre 1,8 y 2,2 :

$$
1,8<\frac{\mathrm{CaO}}{\mathrm{SiO}_{2}-\mathrm{Al}_{3} \mathrm{O}_{3}+\mathrm{Fe}_{\mathrm{g}} \mathrm{O}_{\mathrm{B}}^{-}}<2,2 .
$$

Este módulo, así como los denominados módulo silh́ce y módulo alumínico, pese a sı carácter arbitrario, continúan siendo calculados y catalogađos en los resúmenes estadísticos de los laboratorios de fábricas suponemos que, a falta de mejores argumentos, por espiritu de continuidad o por simple tradición.

Desde ltrego que, si consiguiéramos que estos tres nódulos se mantuvieran constantes, tendríamos una gran regularidad en la fabricación, pero cuando aparecen variaciones en los módulos ya nos es bastante difícil interpretar el sentido más correcto de tales variaciones.

Mayor partido nos parece poder sacar del cociente llamado de saturacion do cal. Empleamos particularmente la fórmula de Lea, tal y como se admitió en la Norma B. S. 12: 1947, siendo:

$$
\begin{aligned}
& \text { Saturación de cal } \%= \\
& \quad=-\frac{100\left\langle\mathrm{CaO}_{0}-0,7 \mathrm{SO}_{3}\right\rangle}{2,8 \mathrm{SiO}_{2}+1,2 \mathrm{Al}_{2} \mathrm{O}_{3}+0,65 \mathrm{Fe}_{2} \mathrm{O}_{3}} .
\end{aligned}
$$

En las N.P. 1956 no se hace ninguna referencia a la saturación de cal. Sin embargo, es una de las variables que tenemos mayor empeño en vigilar después de haber comprobado, prácticamente, la gran influencia que directamente ejerce sobre determinadas propiedades del cemento, como son: la expansibilidad y la resistencia mecánica. Como, por otra parte, estas dos últimas propiedades son aquelias sobre las cuales también ejerce una gran influencia lá fintura del cemento, es difícil conseguir una representación funcional 
simple sin tener en cuenta el conjunto de ambas. variables.

\section{Composición POTENCIAL}

La influencia norteamericana ha introducido en la industria del cemento el concepto de la composición potencial, o sea, la èxpresión cuantitativa del contenido de los componentes más representativos que se han identificado en el cemento portland: silicato tricálcico $\left(\mathrm{SC}_{3}\right)$, silicato bicáicico $\left(\mathrm{SC}_{2}\right)$, aluminato tricálcico $\left(\mathrm{AC}_{\mathrm{a}}\right)$ y alumino-ferrito tetracálcico $\left(\mathrm{AFC}_{4}\right)$.

En las N. P. 1956 no se hace referencia a la composición potencial del cemento, pero sí en el "Caderno de Encargos Provisorio para o Fornecimento o Recepção de Cimentos Especiais», de 10 de octubre de 1946, donde se especifican los siguientes límites para el cemento portland de bajo calor de hidratación :

Silicato tricálcico $\left(\mathrm{SC}_{3}\right)$ máximo $35 \%$

Aluminato tricálcico $\left(A \Upsilon_{3}\right)$ máximo 7 ,

Silicato bicálcico $\left(\mathrm{SC}_{\mathrm{g}}\right)$ mínimo 40 *

Además, en los Métodos de Análisis químico publicados por el "Laboratorio Nacional de Engenharia Civily, en marzo de 1955, se incluye un Apéndice donde se transcri ben las fórmulas de Bogue y Dahl para el cálculo de la composición potencial en equilibrio de cristalización, con los coeficientes dados por A. S. T. M. en la Norma C 150-49. Los porcentajes de los componentes hipotéticos se calculan con aproximación de la primera cifra decimal y se expresan por el número redondo de unidades más próximo. Si se quiere conseguir utna absoluta coincidencia entre la composición centesima! de los óxidos y la composición potencial con dós cifras decimales, se obtienen resultados más exactos con el empleo de las fórmulas dadas por Lea y Desch.

Para el cálculo rápido y aproximado de la composición potencial se ha propuesto el uso de reglas de cálculo y nomogramas.

A los análisis de cementos dados en el apartado 4 , corresponden las siguientes composiciones potenciales:

Composicion potencial

\begin{tabular}{|c|c|c|c|c|}
\hline \multirow{2}{*}{ Componentes } & \multicolumn{2}{|c|}{ Laboratorio I } & \multicolumn{2}{|c|}{ Laboratorio II } \\
\hline & Exacia & Aproximads & Exucta & A proximada \\
\hline $\begin{array}{l}\text { Pérdida al fuego } \\
\mathrm{SC}_{9} \ldots \ldots \ldots \ldots \\
\mathrm{SC}_{\mathrm{g}} \ldots \ldots \ldots \ldots \\
\mathrm{AC}_{3} \ldots \ldots \ldots \\
\mathrm{AFC}_{4} \ldots \ldots \ldots \\
\mathrm{SO}_{4} \mathrm{Ca} \ldots \ldots \\
\mathrm{MgO} \ldots \ldots \\
\mathrm{No} \text { dosificado... }\end{array}$ & $\begin{array}{r}2,58 \% \\
47,68: \\
31,59: \\
11,62 \cdots \\
2,98: \\
3,01: \\
0,29 » \\
0,25 \approx\end{array}$ & $\begin{array}{l}48 \% \\
32 \% \\
12 \% \\
3 » \\
3 »\end{array}$ & $\begin{array}{r}2,43 \% \\
45,37 \% \\
34,25 » \\
11,18 » \\
2,77 » \\
3,08 » \\
0,64 » \\
0,28 »\end{array}$ & $\begin{array}{r}45 \% \\
34 \% \\
11 \% \\
3 \% \\
3 \%\end{array}$ \\
\hline Suxa..... & $100,00 \%$ & $98 \%$ & $100,00 \%$ & $96 \%$ \\
\hline
\end{tabular}

Fué punto muy sujeto a controversia el interés que pueda terier el cálculo de la composición potencial, ya que se demuestia que ésta es más una aproximación muy relativa con respecto a la composición mineralógica del cemento, que una realidad física que se pueda tomar en cuenta para alteriores de. ducciones.

Para el anterior cemento, mediante análisis microscópicos efectuados por el L. N. E. C. en el plano de los «Ensayos Sistemáticos», se ha obtenido:

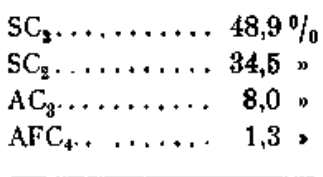


En general, el microscopio cuenta mayor porcentaje de $\mathrm{SC}_{3}$, posiblemente por la disolución sólida de atras sustancias, como alúmina, óxido férrico y magnesia, en los nernos, están ciertos errores que se cometen a sabiendas cuando se calcula la composición antes expuesta y que podriamos designar por composición potencial límite.

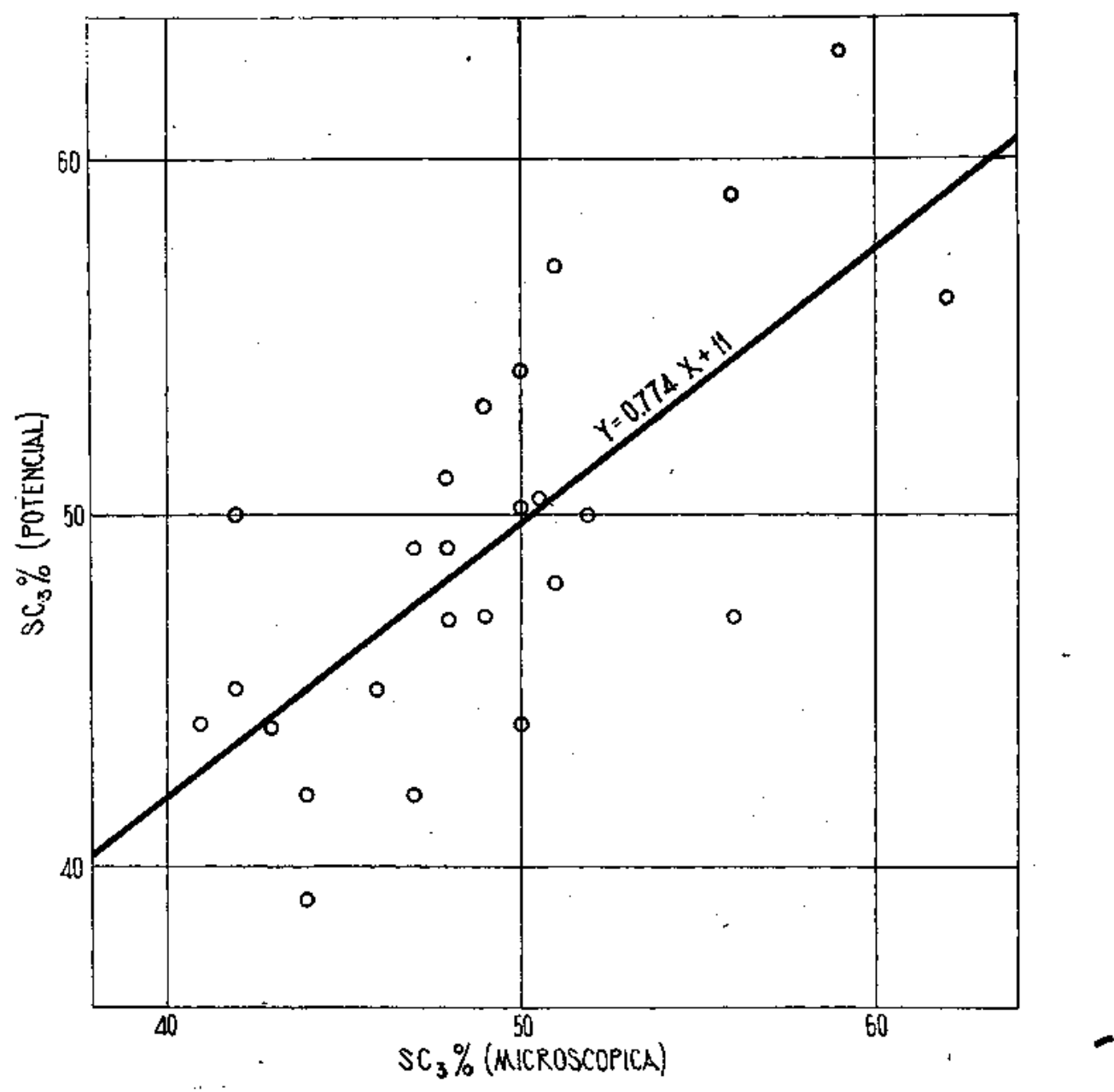

Fig. 1

cristales de alita. El silicato bicálcico puede aparecer aumentado por el efecto de la cal libre. Los aluminatos, en cambio, aparecen siempre disminuídos y no se observó más que muy raramente la recristalización de la magnesia.

Además de estas consideraciones cristaloquímicas, en las cuales no queremos dete-
En primer lugar, habría que descontar de la sílice total el residuo insoluble y de la cal total la cal libre o carbonatada. Operando con cemento, la humedad que contiene y el agua de hidratación del yeso falseà los resultados del análisis de la cal libre, dando valores más altos de lo que en la realidad debieran ser. Pero, obviando esta salvedad, introduciendo estas dos correcciones, se ob- 
tendría una nueva composición potencial corregida, en la cual se alterarian los porcentajes de $\mathrm{SC}_{3} \mathrm{y}$ de $\mathrm{SC}_{2}$, permaneciendo invariables los aluminatos $\mathrm{AC}_{3}$ y $\mathrm{AFC}_{4}$.

Los óxidos menos abundantes, como el $\mathrm{FeO}$, el $\mathrm{TiO}_{2}$, el $\mathrm{Mn}_{2} \mathrm{O}_{3}$ y el $\mathrm{P}_{2} \mathrm{O}_{5}$, no son tomados en cuenta y aparecen englobados entre los componentes principales. Las im-
Recordemos, además, los límites impuestos a los componentes potenciales en los cementos de bajo calor de hidratación. En la figura 4 se representan los $\mathrm{SC}_{3}$ potenciales y los calores de hidratación obtenidos veintiocho días después del fraguado del cemento. Nuevamente aparece una gran dispersión de los resultados. Aun cuando se trata de cementos en los cuales el contenido de alu-

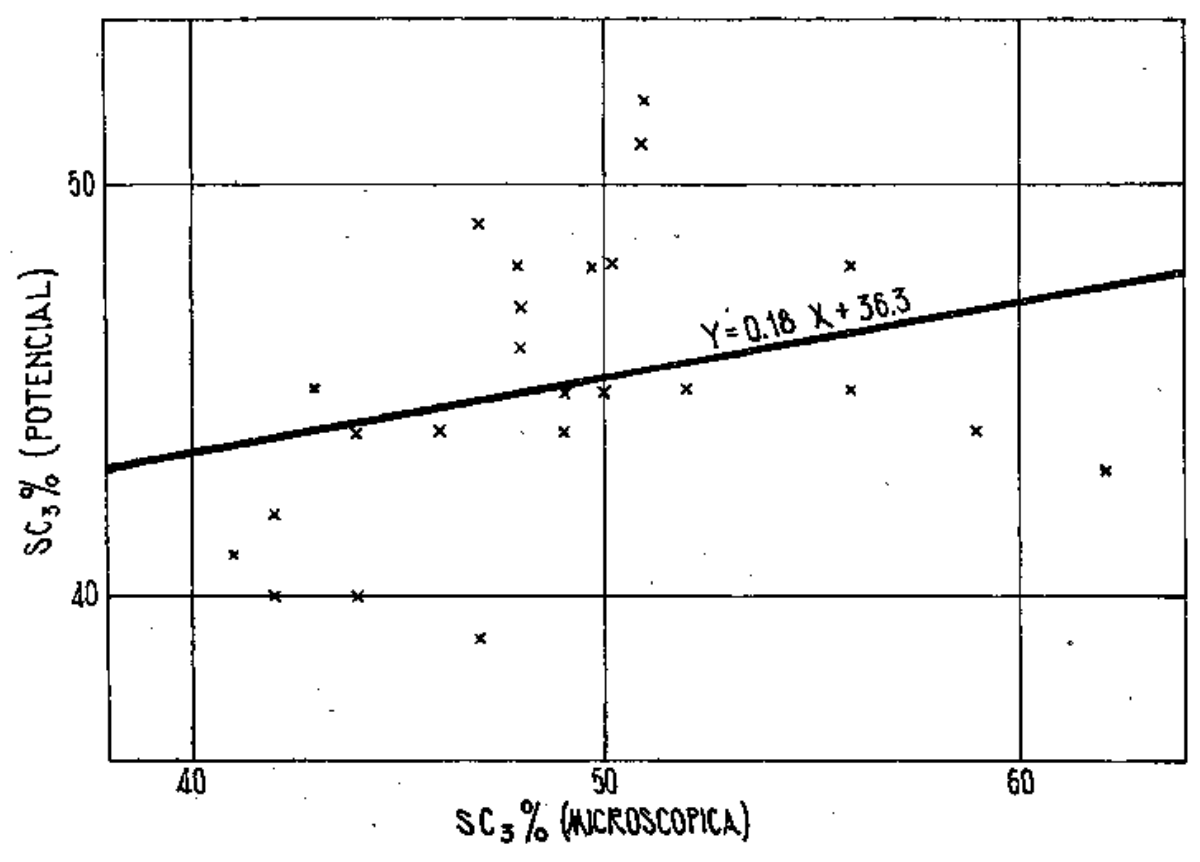

Fig. 2 .

purezas del yesd y el hierro adquirido por desgaste de los cuerpos moledores, entran en la composición potencial como si estuviesen combinados en los minerales del clínker. Y así otros errores, que nunca son corregidos y que contribuyen a falsear la llamada "composición potencial».

Las figuras 1,2 y 3 ponen de manifièsto la escasa correspondencia entre el $\mathrm{SC}_{3}$ potencial y el $\mathrm{SC}_{3}$ microscópico, destacando la enorme dispersión de los resultados. minatos varía dentro de estrechos límites, la dispersión continúa siendo francamente desalentadora.

Por todas estas razones, entendemos que el cálculo de la composición potencial tiene poca utilidad en nuestra fabricación.

\section{7.-DENSIDADES REAL Y APARENTE}

El peso espécífico, comúnmente denominado densidad real, es un dato que tiene esca- 
so valor para el control de calidad en la fabricación del cemento.
Un peso específico muy bajo hace sospechar la existencia de incocidos y aun de adi-

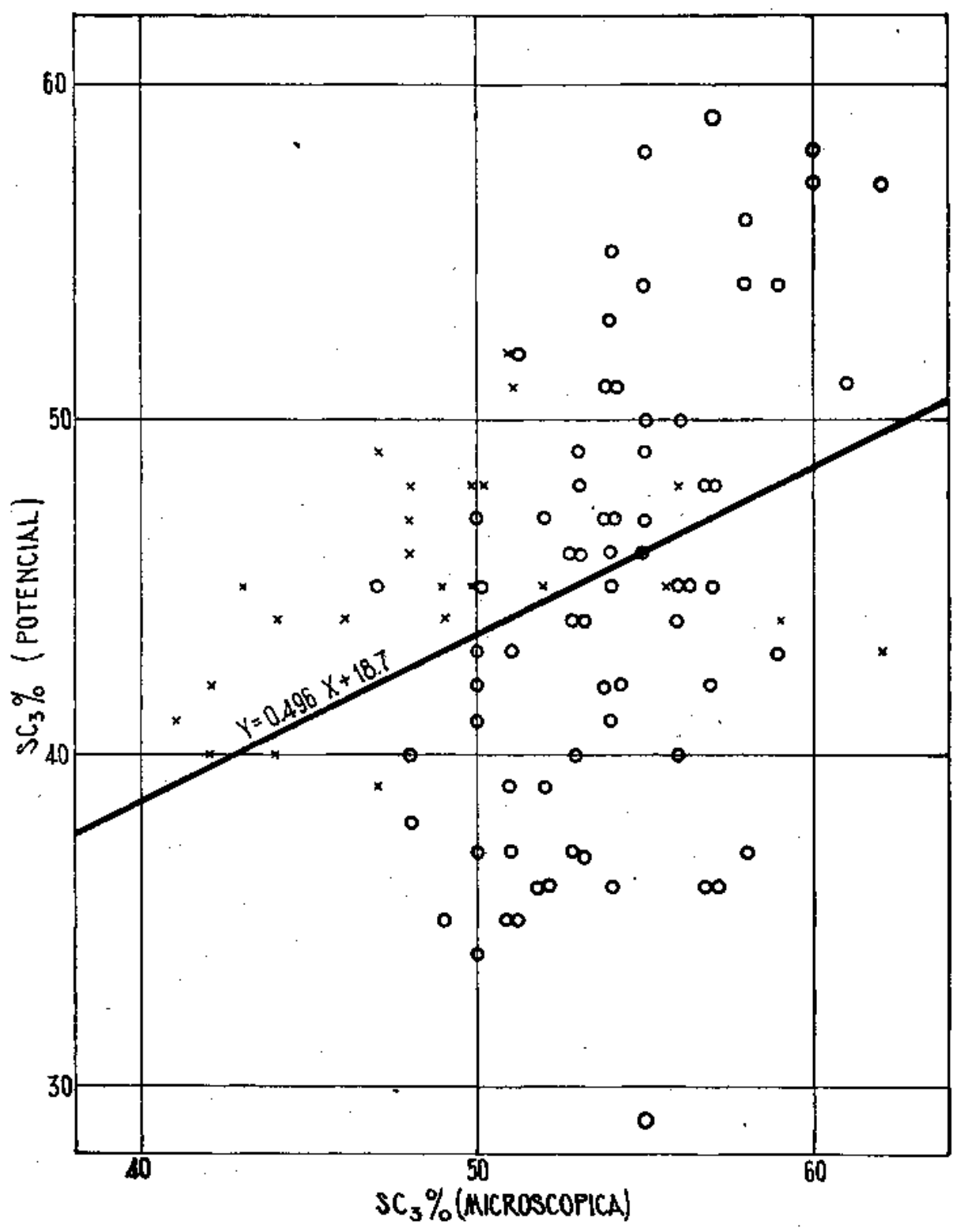

Fig. 3

Un peso específico elevado puede, apenas, indicar el predominio de ciertos minerales como el AFC, que, siendo densos, poco influyen en el desarrollo de las resistencias mecánicas. ciones crudas, por ello menos densas, efectuadas en el momento de la molienda. Las adiciones de materiales densos no serían nunca reconocidas por la simple determinación del peso específico. 


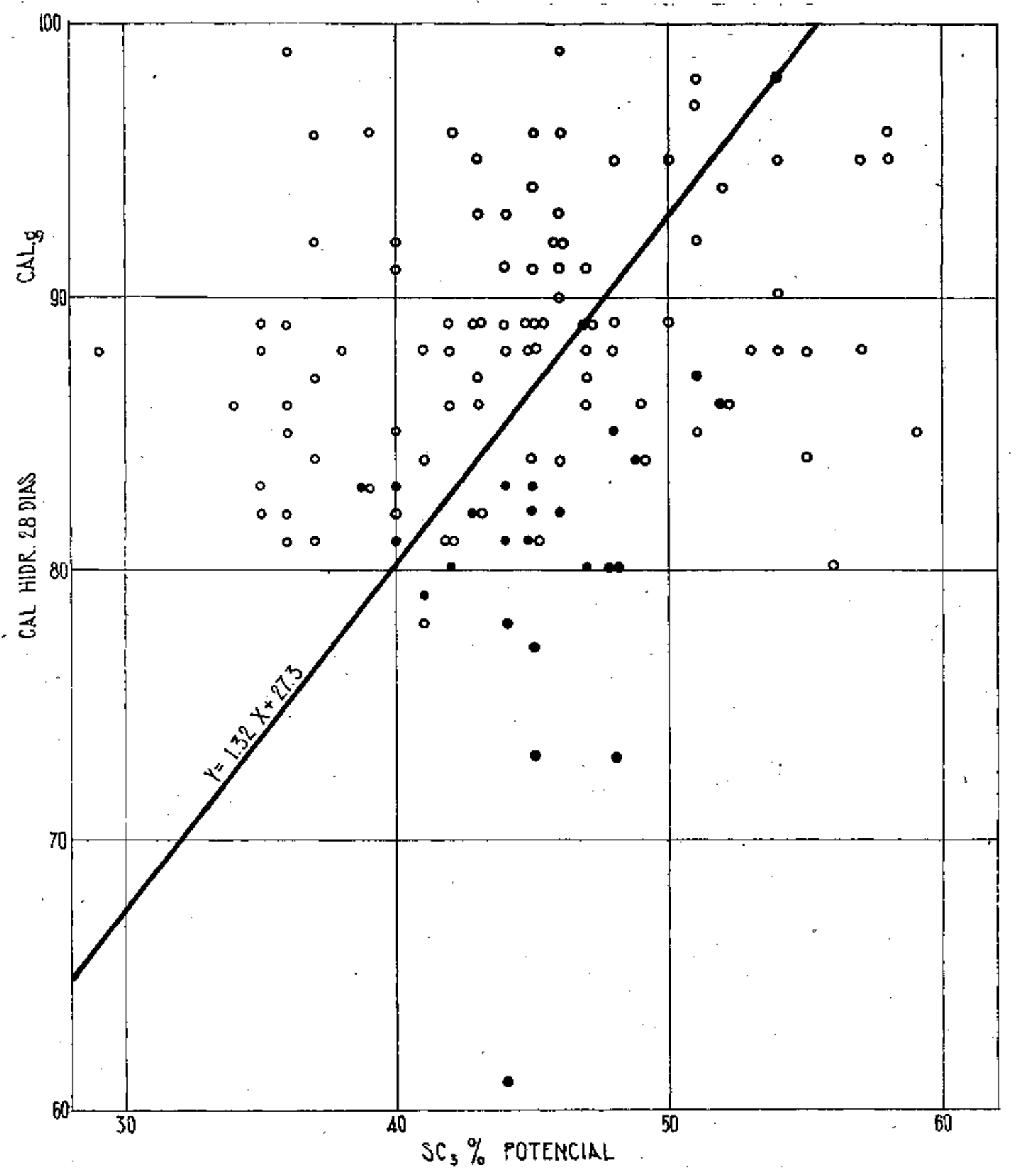

Fíg. 4

(C) Consejo Superior de Investigaciones Científicas

Licencia Creative Commons 3.0 España (CC-by)

http://materconstrucc.revistas.csic.es 
La nueva N. P. 1956 no altera el clásico método de determinación del peso especifico empleando el volumenómetro de "Le Chateliern, y tampoco cambia el aritiguo limite inferior, que se establece en $3,05 \mathrm{~g} \mathrm{~cm}^{-3}$, como en España y en otros muchos paises. Suiza, en cambio, admite una posibilidad de variación comprendida entre 3,0 y 3,2 .

Para una determinación normal del peso especifico se emplean 64-65 $\mathrm{g}$ de cemento, $\mathrm{y}$ desde su pesada hasta la lectura final pasan unas dos horas y media.

No se especifica la determinación de la densidad aparente o baridad $\mathrm{y}$, sin embargo, conceptuamos que este ensayo tiene un verdadero interés para el control de calidad en la fabricación del cemento. Es bien sabido que los cementos muy finos son los de menor densidad aparente. Si pretendemos verificar el funcionamiento de los molinos de refino, la determinación de la densidad aparente nos proporciona un medio de control, rápido y certero.

En cada caso estarán determinados los lím mites de precaución y de peligro, pero, en general, siempre que la densidad tparente de un cemento no meteorizado sea superior a un kilogramo por litro, no se pueden esperar ni una adecuada finmra, ni unas altas resistencias con semejante material.

\section{Finura}

L.a verificación de la finura en el cemento acabado tiene un doble interés, ctralitativo y económico. Cualitativamente interesa conseguir una finura adecuada para que el cemento desarrolle con rapidez sus cualidades de resistencia mecánica en las obras donde sea empleado. Tampoco es posible conseguir una estabilidad de volumen sin dar al producto una finura suficiente. Ahora bien, un exceso de finura puede no contributir mucho al incremento de las características de resistencia y estabilidad, y puede, eso si, resultar altamente onerosa por el consumo de energía suplementario que exige en las operaciones de molienda.

Por estas razones, los laboratorios de fábricas de cemento entendemos que no deben escatimarse medios para liegar al más profundo conocimiento del problema de la finura. Por nuestra parte, tenemos una cierta experiencia que abarca los aparatos siguientes: Tamices, Flourómetro, Aparato de pipeta, Turbidímetro de Wagner y Permeabilímetro de Blaine.

Nos adelantamos a salir al paso de aquelios que pretendan que, tanta variedad de medios, en vez de orientarnos, puede sumergirnos ell una confusión pavorosa $\mathrm{y}$, a fin de cucntas, nos quedemos sin saber cuál es el más fino entre dos cementos ensayados. Afortunadamente para todos, las cosas no suceden asi.

\section{a) Tamices}

$E_{1}$ las Normas Portuguesas de 1956 se hace referencia a dos tamices, que son los siguientes:

\begin{tabular}{|c|c|c|}
\hline $\begin{array}{l}\text { Námero de } \\
\text { A S.T.M. }\end{array}$ & $\begin{array}{c}\text { Núm, de mallas } \\
(\mathrm{DIN})\end{array}$ & $\begin{array}{c}\text { Abertura de malias } \\
(\mathrm{N}, \mathrm{P})\end{array}$ \\
\hline 170 & 4.900 mallas $/ \mathrm{cm} .^{2}$ & $0,088 \pm 0,0065 \mathrm{~mm}$ \\
\hline 325 & 16.900 & $0,044+0,003 \mathrm{~mm}$ \\
\hline
\end{tabular}

Para el primer tamiz se prescribe un residuo máximo de 10 por 100 , que es el límite más bajo impuesto por los países que aún 
admiten la operación del tamizado como norma para Ja definición de la finura.

El límite para el tamiz de 44 micras no está especificado. El empleo de este tamiz aparece como una consecuencia de la determinación de la finura por medio del turbidímetro.

Ventos, pues, que el clásico tamiz de 4.900 mallas por $\mathrm{cm}^{2}$ continúa gozando del favor oficial y sigue prestando importantes servicios, creemos que en todas las fábricas de cemento del mundo. Nosotros lo empleamos para las determinaciones horarias de la finura, tanto en la molienda de crudo como en la de cemento. El tamizado lo efectuamos mecánicamente, en un pequeño vibrador de $68 \mathrm{~W}$ de potencia y 1.300 r. p. m., precedido, antes, de una operación manual, en la cual ya se elimina gran parte del polvo. Los crudos deben ser tamizados en corriente de agua, y lo propio se hace, según está normalizado, con los residuos sobre el tamiz número 325 .

Según está especificado, el residuo sobre el tamiz de 4.900 mallas se expresa por In media de tres determinaciones, efectuadas cada una de ellas con 50 gramos de cemento. Una determinación conforme con las Normas tarda en efectuarse unos cuarenta y cinco minutos. Una determinación simple, demora quince minutos.

La precisión de los ensayos de tamizado no debe sobreestimarse. Repitiendo varias veces la operación con un mismo cemento, la dispersión de los resultados es considerable. Matouschek encontró errores medios de 6,8 por 100 para los cementos normales y de 21,6 por 100 para los supercementos. E1 error medio aumenta en valor relativo cuando disminuyen los residuos. Efectuando cinco determinaciones sobre dos muestras dife- rentes, hemos obtenido los siguientes resultados:

\begin{tabular}{|c|c|c|}
\hline & $\underset{\% /}{\text { Cemento }} \mathrm{E}$ & Cemento $\mathrm{F}$ \\
\hline & $\begin{array}{l}1,7 \\
1,5 \\
1,4 \\
1,3 \\
1,1 \\
\end{array}$ & $\begin{array}{l}1,2 \\
0,9 \\
0,9 \\
0,8 \\
0,6 \\
\end{array}$ \\
\hline $\begin{array}{l}\text { Media. ...... . . . } \\
\text { Error normal....... } \\
\text { Etror normal relativo }\end{array}$ & $\begin{array}{r}1,4 \\
0,2 \\
14,8\end{array}$ & $\begin{array}{r}0,9 \\
0,2 \\
19,8\end{array}$ \\
\hline
\end{tabular}

Los residuos de los cementos portugueses determinados en el plan de los «Ensayos Sistemáticos» raramente pasan de $\mathbf{8}$ por $\mathbf{1 0 0}$. 'Así, las medias oljtenidas en 1950 fueron:

\begin{tabular}{c|c}
\hline Cementos & $\begin{array}{c}\text { Residuos sobre } \\
\text { tamiz de } 88 \text { micras } \\
\%\end{array}$ \\
\hline & \\
A & 3,6 \\
B & 5,6 \\
C & 4,8 \\
D & 4,5 \\
E & 1,7 \\
\hline
\end{tabular}

Estos resultados, elocuentes en sí mismos, indican que, por el simple tamizado, carecemos de" toda información sobre la distribución de los granos del 95 por 100 o más del peso de cemento qụe atravesó las mallas del tamiz, y está bastante probada la importancia que tiene esta distribución en otras propiedades cualitativas del material.

\section{1) Flowrómetro}

Desde hace mucho tiempo, la industria cementera tiene en gran aprecio la información que suelen dar los separadores de aire o flourómetros. Por cada aparato y para cada tipo de cemento se puede determinar una flourometría tipo, de la cual no convie- 
ne apartarse. Esta finura proporciona un medio más, cómodo y digno de fe, para la. vigilancia de las operaciones de molienda. Nosotros lo empleamos efectuando una determinación cada cuatro horas. El peso de cemento sometido a la corriente de aire es
Quizá sea la divergencia de los resultados presentados por inos y otros aparatos, uno de los motivos por los cuales los flourómetros van perdiendo estima. Sus determinaciones carecen de valor absoluto, y no hay que pensar en que las separaciones efectua-

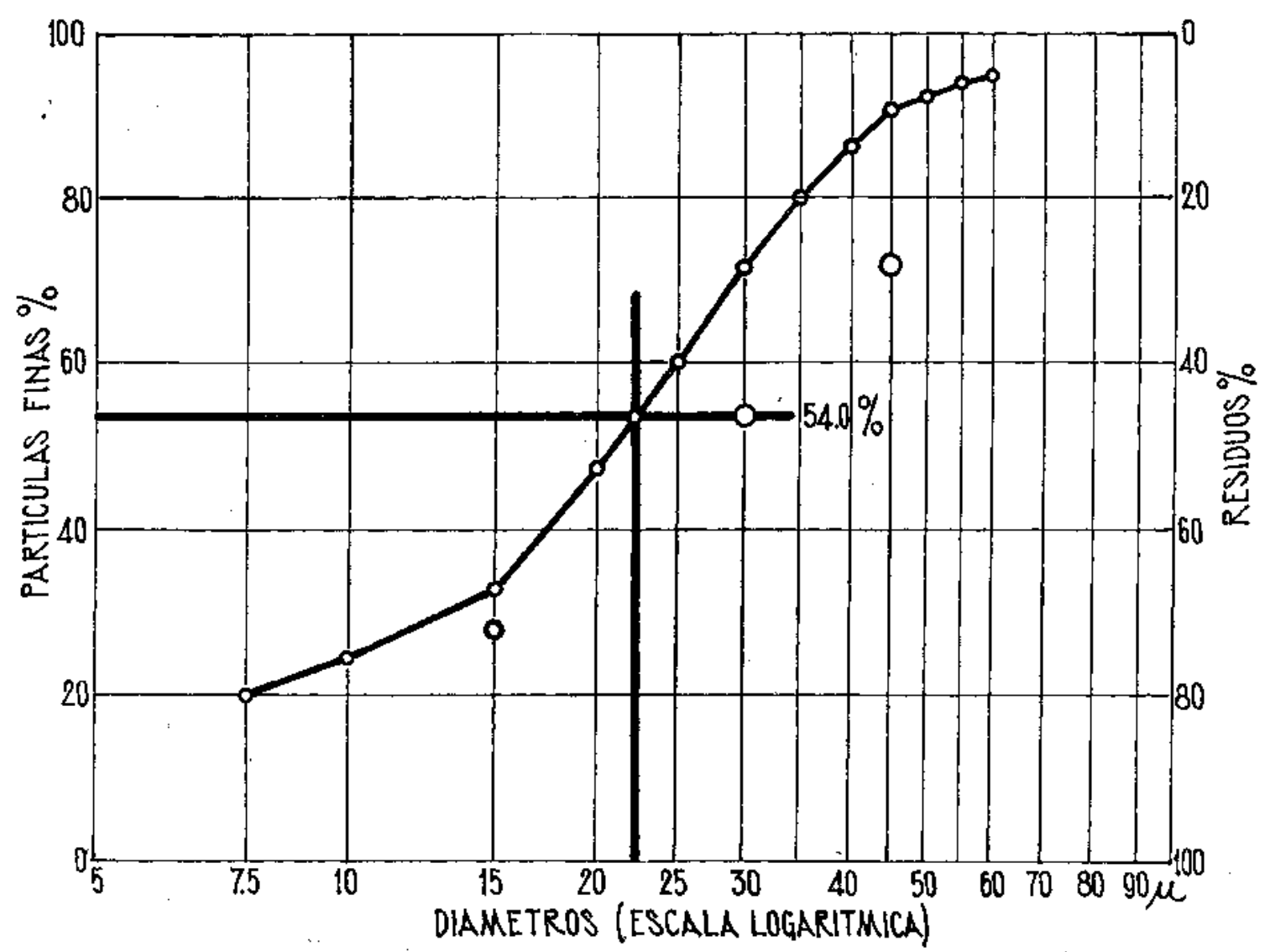

Fig. 5

de 5 gramos y la duración total del ensayo cuarenta minutos, permaneciendo en el separador durante veinticinco minutos.

Notemos que, a pesar de todo, el flourómetro parece caier en desuso y, en todo caso, no goza del favor oficial. Suiza fué el único país que lo adoptó en sus Normas de 1933 , suprimiéndolo veinte años más tarde, en las Normas de 1953 . das a 15,30 ó 45 micras correspondan a un rigor matemático. En las figuras 5 y 6 se ponen de manifiesto las discrepancias de las determinaciones efectuadas con distintos aparatos en varios laboratorios. Sin embargo, haremos resaltar que las determinaciones flourométricas son de una gran precisión, con dispersiones mucho menores que las de otros aparatos. Así, calibrando un flouró- 
metro con espato-flúor, se han obtenido los residuos siguientes:

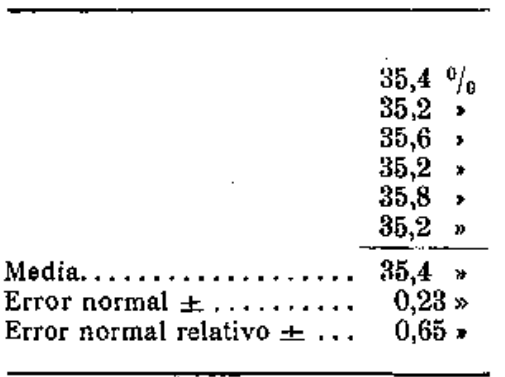

una determinación muy cuidadosa que puede dar lugar a errores serios si no se procede con mucha exactitud. Su empleo, por tanto, no entra en el campo del control de fabricación y to limitamos para contados casos de investigación.

\section{d) Tubidimetro de Wagner}

La determinación de la superficie específica mediante el turbidimetro de Wagner,' ya

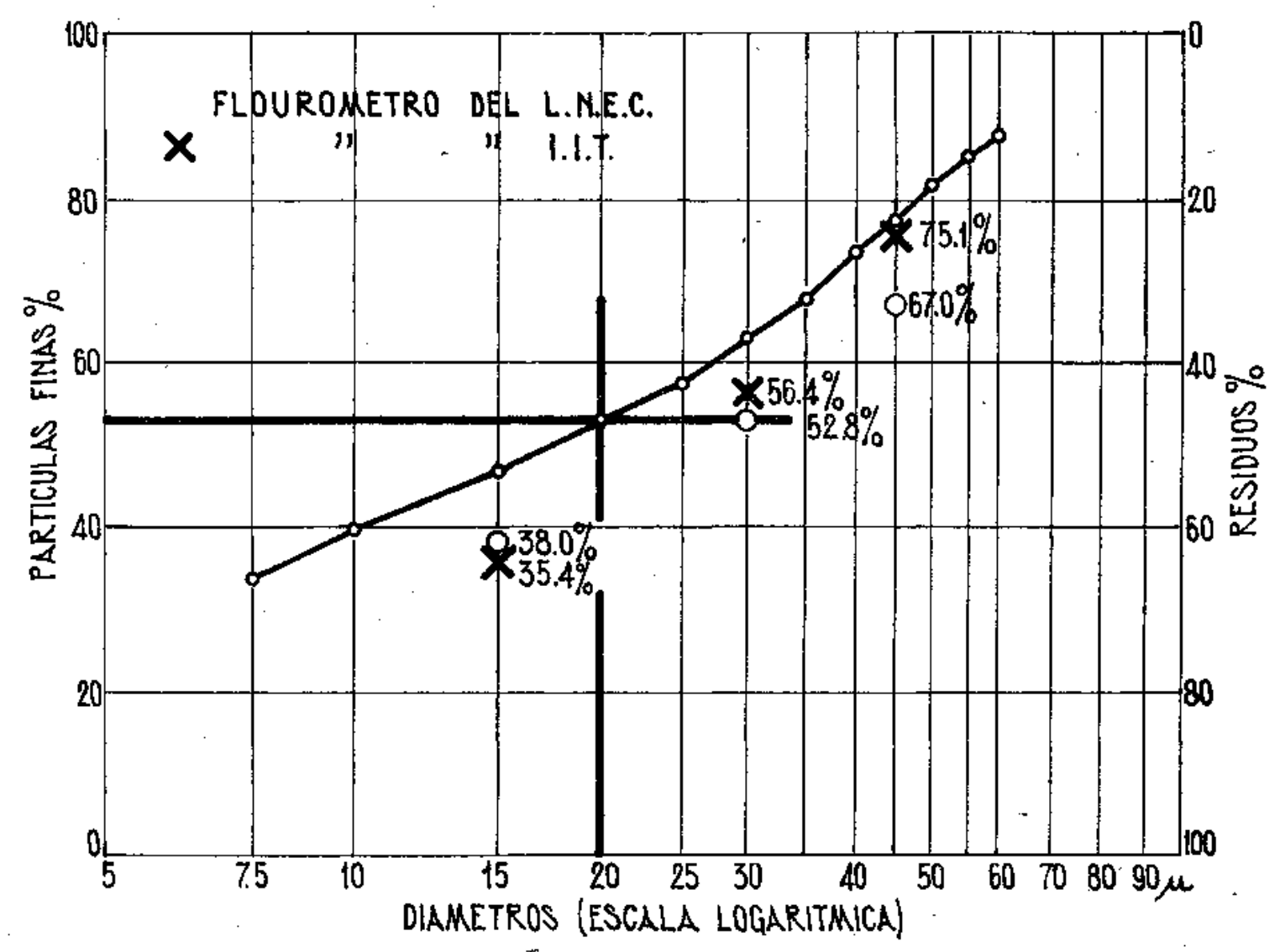

Fig. 6

\section{c) Aparato de pipeta}

La pipeta de Andreasen y otros aparatos análogos exigen un tiempo muy variable para una determinación completa, pudiendo llegar a unas horas cuando se quieren sedimentar fracciones muy finas. Es, ađemás, estaba especificada en el "Caderno de Encargos Provisorio para o Fornecimento e Recepção de Cimentos Especiais» de 1946; últimamente se ha introducido — sin carácter obligatorio- en las N. P. 1956. Influyeron en esta adoptación, la experiencia adquirida durante diez años y la posibilidad de poder 
deterninar, utilizando las indicaciones del turbidimetro, la curva granulométrica del cemento, lo que nos permite juzgar la infinencia de la finura en sus propiedades. diato del funcionamiento de los molinos. Un ensayo completo exige la determinación previa del peso específico (dos horas veinte minutos), la determinación del residuo sobre el

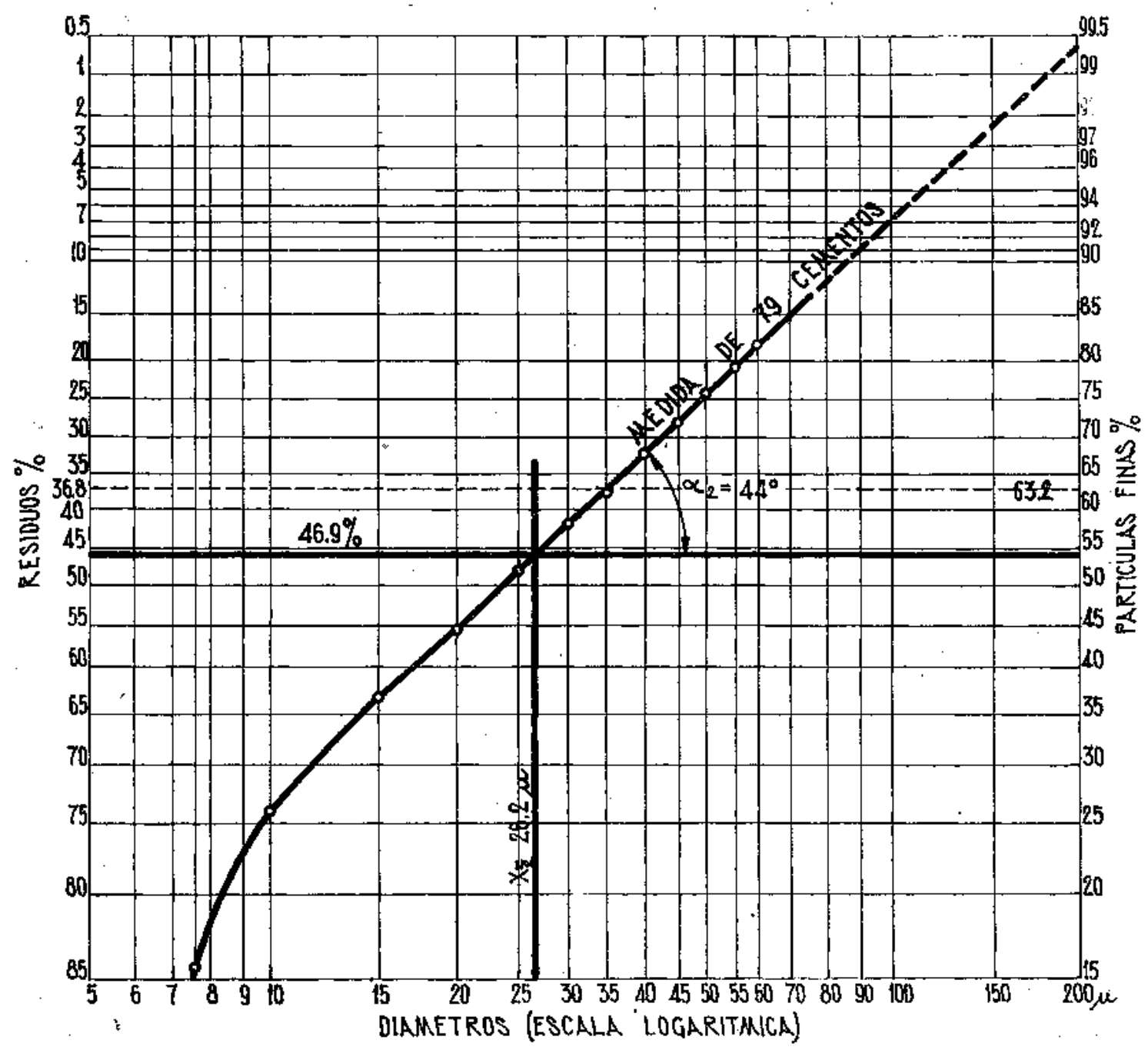

Fig. 7

El valor mínimo especificado es de $\mathbf{1 . 5 0 0}$ $\mathrm{cm}^{2} \mathrm{~g}^{-1} \mathrm{y}$, como puede verse, está normalmente sobrepasado por los cementos portland portugueses.

En nutestro laboratorio de fábrica poseemos el turbidímetro y trabajamos normalmente con él, pero no para el control inme- témiz núm. 325 (quince minutos) y el ensa yo con el turbidimetro (cuarenta minutos). El tiempo total mínimo es, pues, de tres horas y cuarto, excesivo para el control inmediato. Si bien la determinación pura y simple de la superficie espécífica, siguiendo el modelo de cálculo normalizado, es relativamente fácil, la determinación de las superfi- 
cies parciales y de la curva granulométrica ga exige la atención de un calculista experto.

Superficie especifica Wagner de los cementos portugueses en 1955 . Resultados obtenidos por el L.N.E.C.

\begin{tabular}{c|cc}
\hline Cementos & \multicolumn{2}{|c}{ Superticles } \\
\hline & & \\
$\mathrm{A}$ & $1.783 \mathrm{~cm}^{*} \mathrm{~g}^{-1}$ \\
$\mathrm{~B}$ & 1.669 & $"$ \\
$\mathrm{C}$ & 1.831 & $n$ \\
$\mathrm{D}$ & 1.916 & $"$ \\
$\mathrm{E}$ & 1.976 & \\
\hline
\end{tabular}

Solamente en casos de invegtigación efectuamos el trazado de la curva granulométrica. Cuando lo hacemos, solemos encontrarnos conque la granulometría se aparta de la recta que daría sobre una cuadricula logarítmica-doble logarítmica, si la distribución de partículas estuviese de acuerdo con la ley de Rosin y Rammler (figura 7). En un gráfico, media de $\mathbf{7 9}$ ensayos de cementos, encontramos que la separación de nuestro flotrómetro F. L. Smiđth se efectuaba al nivel de 26 micras. Una correspondencia aproximada entre los residuos flourométri$\cos$ y la superficie especifica Wagner viene dada por la ecuación:

$$
\mathrm{S}_{w}=4.800\left(2-\log \mathrm{R}_{f}\right)
$$

y se representa gráficamente en la figura 8 .

\section{e) Permeabilimetro de Blaine}

La determinación de la superficie específica por medio del permeabilimetro de Blaine no ha sido adoptada en las N. P. 1956, pero entró en el cuadro de los «Ensayos Sistemáticosn de los cementos portugueses. Los resultados medios obtenidos, fueron:
Superficie especifica Blaine de los cementos portugueses en 1955. Resultados obtenidos por et L.N.E.C.

\begin{tabular}{|c|c|}
\hline Comentos & Superficiess \\
\hline A & $3.399 \mathrm{~cm}^{2} \mathrm{~g}^{-}$ \\
\hline B & $3.126 \Rightarrow$ \\
\hline $\mathrm{C}$ & 3.317 \\
\hline D & 3.568 , \\
\hline$E$ & 3.510 \\
\hline
\end{tabular}

La determinación de la superficie especí. fica con el permeabilímetro, suponiendo constante la densidad del cemento, y empleando tablas de valores, no exige más de quince minutos, aproximadamente igual tiempo que el invertido en la determinación de un residuo con el tami $z$ de $\mathbf{4 . 9 0 0}$ mallas. Por este motivo el permeabilimetro se convierte en un buen instrumento para el control permanente de la marcha de los molinos, tanto de crudo como de cemento. En nuestro caso alternamos los ensayos de permeabilidad con los ensayos por el flourómetro, efectuándose dos de cada clase por molino y por turno.

Por los valores dados anteriormente vemos que la superficie específica obtenida por el método de Blaine es, aproximadamente, el doble de la que se obtiene por el método de Wagner. Sin embargo, una fórmula aditiva se ajusta mejor a los resultados. El L. N. E. C. proptuso la fórmula:

$$
\mathrm{S}_{\mathrm{B}}=\left(\mathrm{S}_{w}+1.820\right) \mathrm{cm}^{2} \mathrm{~g}^{-1} \text {. }
$$

En nuestro laboratorio de fábrica encontramos:

$$
\mathrm{S}_{\mathrm{B}}=\left(\mathrm{S}_{w}+1.890\right) \mathrm{cm}^{2} \mathrm{~g}^{-1}
$$

La correspondencia entre ei permeabilímetro y el flourómetro se representa gráficamente en la figura 8 , y se estableció en:

$$
\mathrm{S}_{\mathrm{B}}=8.940\left(2-\log \mathrm{R}_{f}\right) \mathrm{cm}^{2} \mathrm{~g}^{-1}
$$




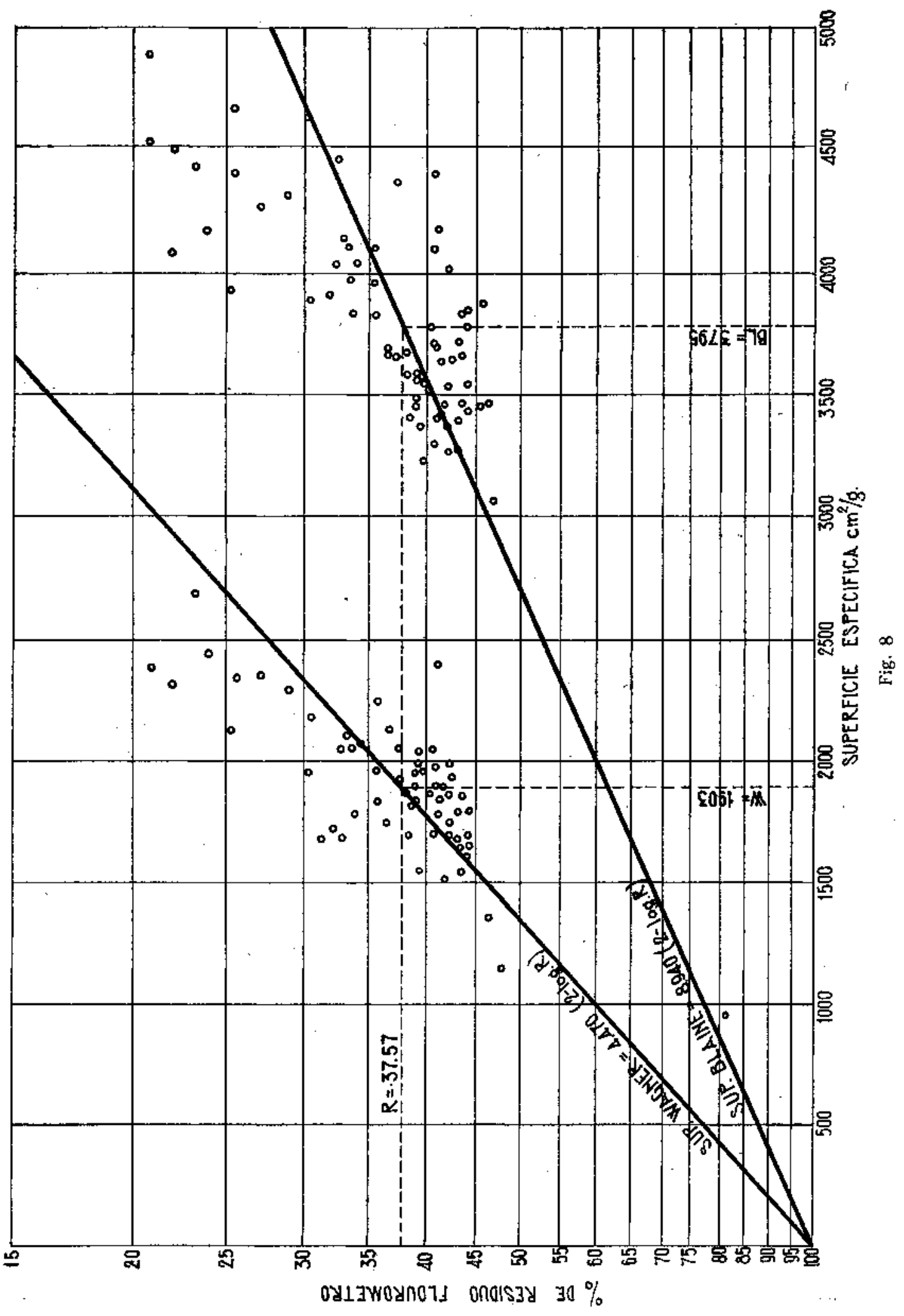


Estas fórmttlas de correspondencia acostumbran a presentar tnos resultados muy -dispersos, pero, según las determinaciones efectuadas por el L. N. E. C.., el error relativo de las determinaciones efectuadas por medio del permeabilímetro es menor que cuando se opera con el turbidímetro.

\section{9. irRaguado}

Las N. P. 1956 no introdujeron variaciones en la determinación del fraguado. Tan solamente se especifica que debe principiar de una a ocho horas a contar del comienzo del amasado. El término de las ocho horas parece ser demasiado lato, si se tiene en cuenta que los cementos portugueses suelen ser más bien rápidos, comenzando a fraguar de dos horas y media a tres horas y acabando de cuatro a seis horas.

El aparato de Vicat sigue siendo el que se emplea, tanto oficialmente como en los laboratorios de fábrica. Si bien son de ger neral conocimiento otras técnicas más modernas y rigurosas, tan solamente se han ensayado en ciertas investigaciones, y no puede decirse que hayan sido adoptadas como métodos de control permanente.

En la fábrica tomamos 625 gramos de cemento, en vez de un kilogramo. Aquella can-

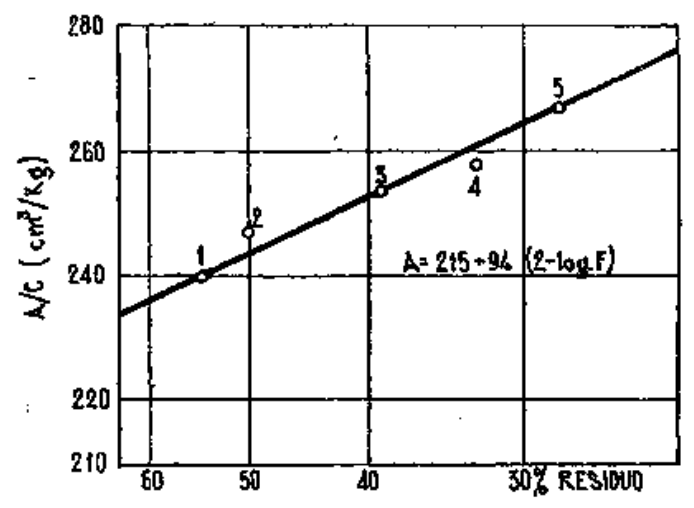

Fig. 9 tidad da pasta más que suficiente para llenar el moide tronco-cónico y tres agujas de Le Chatelier. La proporción de agua por kilo-

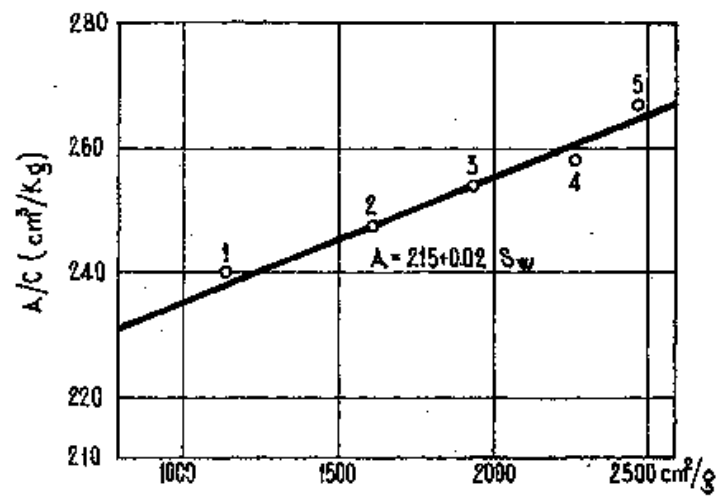

Fig. 10

gramos de cemento se obtiene exactamente multiplicando el agua gastada pot 1,6. E1 tiempo de amásado se puede reducir a cuatro minutos, en virtud del menor peso de cemento trabajado.

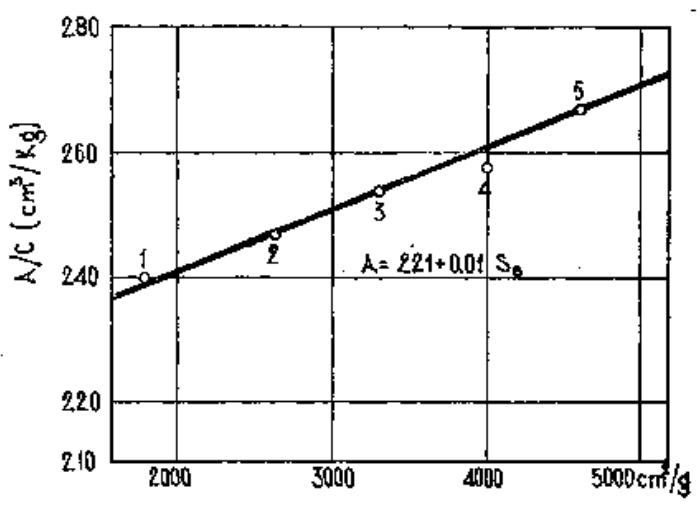

Fig. 11

Merece, para nosotros, especial atención la cantidad de agua necesaria para obtener la pasta de consistencia normal. Sobre su significación preparamos un estudio que creemos será bastante interesante. En cualquier caso, siendo el agua de la pasta función de la finura, parece evidente que, para un cemento determinado, la exigencia de una ele- 
vada cantidad de agua sea indicación de calidad. En las figuras 9,10 y 11 se pone de manifiesto la relación existente entre el aguá de la pasta normal y las finuras determinadas por el flourómetro, el turbidímetro o el el paralelismo entre las dos últimas líneas es más evidente que en relación con la curva de las resistencias; pero, en general, los mayores contenidos de agua corresponden a las más aitas resistencias.

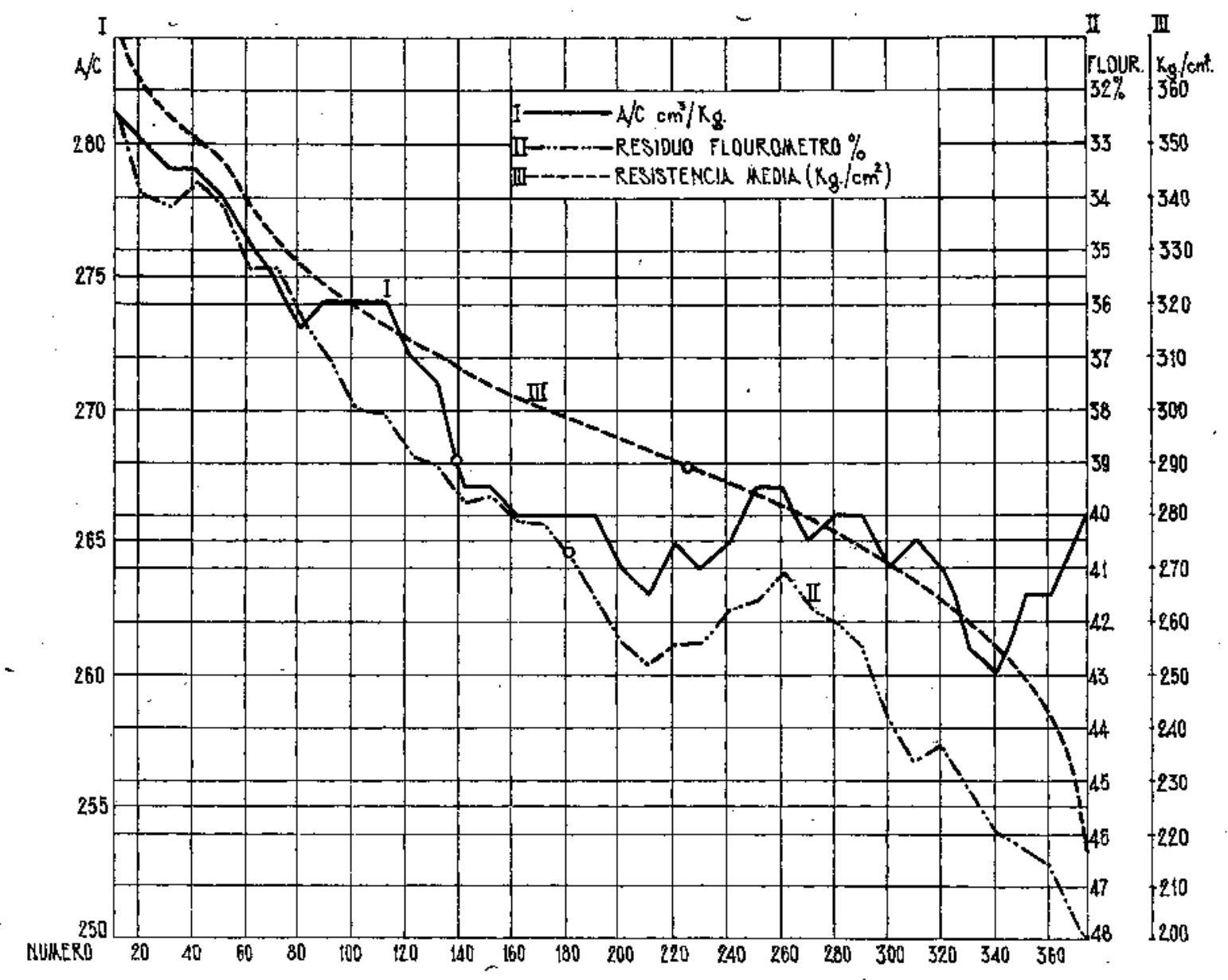

Fig. 12

permeabilímetro. En la figura 12 se han ordenado 375 muestras de cementos diferentes, según sus resistencias mecánicas decrecientes. Se han agrupado los resultados de diez en diez, y junto a la curva de las resistencias decrecientes se han trazado las variaciones del agua necesaria para la pasta de consistencia normal y de la finura expresada por residuos flourométricos. Desde luego,

\section{Estabilidad DE yoLUMeN}

Las N. P. 1956 continúan fieles a la determinación de la expansibilidad del cemento mediante el ensayo simple de Le Chatelier. Se admite una expansibilidad máxima de $4 \mathrm{~mm}$, siendo ésta la media de tres ensayos simultáneos y realizados con una misma 
pasta. Raramente es excedido este límite, to cual no es de extrañar, dadas las condiciones de alta finura que cumplen todos los cementos portugueses.

En ensayos de laboratorio, y operando con muestras de cementos de grados de coc-
Es posible que las agujas de Le Chatelier no sean el mejor medio para la determinación de la estabilidad de volumen de los cementos. Tal vez sea un proceso tan inadecuado como la determinación de la finura por medio del tamiz de 4.900 mallas. Como se sabe, en los EE. UU. se adoptó como

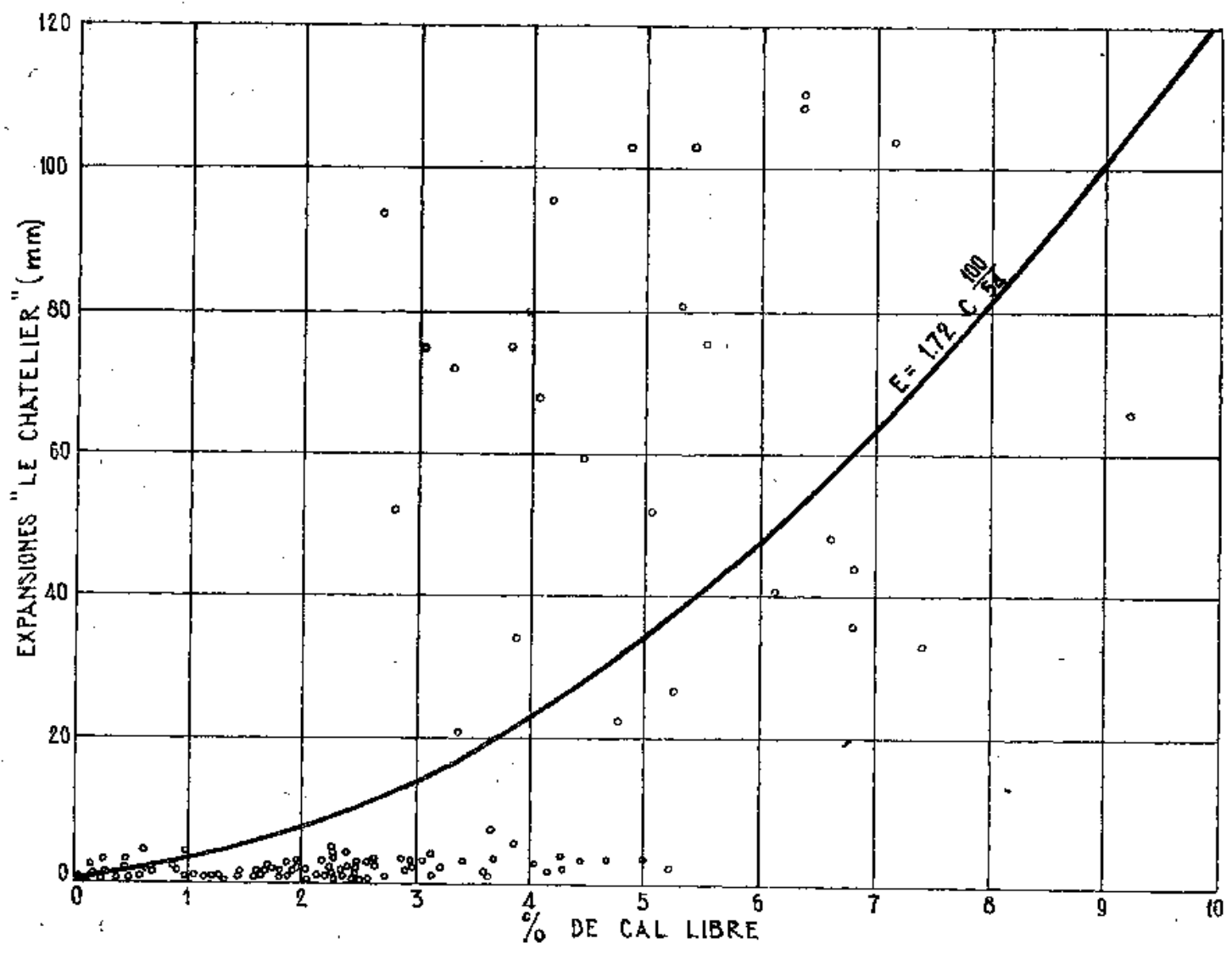

Fig. 13

ción muy variados, es posible obtener cementos expansivos y hasta de gran expansibilidad, como se ve en la figura 13 , en la cual se representan las expansililidades normales en función de la cal libre. Hasta un 3 por 100 de cal libre, las expansiones suelen ser pequeñas. Pasado este límite ya aparecen expansiones altas, observándose una gran dispersión de los resultados, en parte explicable por diferencias de finura. norma legal el ensayo de estabilidad de volumen sometiendo prismas de cemento a la acción del vapor de agua a presión de $21 \mathrm{~kg} \mathrm{~cm}^{-2}$, correspondiente a la temperatura de $216^{\circ} \mathrm{C}$, en un autoclave y durante tres horas por lo menos. La expansibilidad determinadal según este método ofrece mayor precisión y mayor sensibilidad. Lamentamos no tener experiencia propia sobre los ensayos con autoclave $y$, por este motivo, 
no podemos sumarnos a las críticas -farorables o adversas - que se han hecho del procedimiento americano. Los restitados que tenemos a la vista, obtenidos en otros laboratorios, son realmente favorables para los cementos de nuestra producción. Es poco probable que, en ausencia de magnesia cristalizada, con menos de $\mathbf{1 , 5}$ por $\mathbf{1 0 0}$ de ca! libre y superficie especifica Wagner superior a 1.800, un cemento portland no pase satisfactoriamente por la dura prueba del autoclave. Los cementos portugueses, en general. cumplen los requisitos exigidos por las Normas de la A. S. T. M. sobre la estabilidad del volumen. El autoclave, muy particularmente, se va introduciendo en los laboratorios de fábrica como un metodo insustituible para este ensayo de calidad.

Otro punto a tocar, siquiera sea brevemente, ya que en las $\Lambda^{\dagger}$. P. 1950 no se lace ninguna referencia, es la parte relativa a la contracción y fisuración del cemento. En nuestro laboratorio de fábrica hemos comenzado a experimentar las técnicas propuestas por la AFNOR, empleando probetas prismáticas de pasta pura, cle $40 \times 40 \times 160$ milimetros, para la medida de la contratción, y anillos de pasta, de 90 y $127 \mathrm{~mm}$ de diámetro y $40 \mathrm{~mm}$. de altura, para los ensayos de fisuración. Esperamos gue los resultados de estos ensayos nos permitan introducirios como método corriente para el control permanente de la calidad de nuestros cementos.

\section{RESTSTENCIA MECANICA}

Ea resistencia mecánićc es, sin duda; el carácter que mejor define la calidad de un cemento $y$, por lo menos, el que más suele interesar al usuario. La composición química y la finura, sólo interesan en la medi- da exł que contribuyen a líl consecución de unas altas resistencias mecánicas.

Por ser de todos sobradamente conocidas las influencias ejêrcidas sobre los resultados finales por el tipo de arena, cantidad de agua de amasado, forma de los moldes y modo de llenarlos, el procedimiento adoptado para la ejecución de los ensayos de resistencia mecánica adquiere una importancia capital, fuera de toda ponderación. En las fábricas se suele mirar con desconfianza todo proyecto que altere sustancialmente los métodos de ensayo, aunque no sea por otro motivo que nuestro interés en mantener los cuadros estadísticos que ponen de manifiesto la evolución de las resistencias mecánicas de los cementos producidos en función deí tiempo. Al cambiar las Normas se rompe lá continuidad, y la comparación de la calidad en relación con los cementos producidos en otro tiempo ya no se evidencia tan claramente como se desearía.

Entre las N. P. 1930 y las N. P. 19\%(3, se puede establecer el siguiente cuadro comparativo:

\begin{tabular}{|c|c|c|}
\hline & N.P. 1980 & N.P 1956 \\
\hline Arena normal. . . . . . . & Simple & Compuesta \\
\hline Limites grantulométricos... & 1 a $1.5 \mathrm{~mm}$ & 0 a $1,68 \mathrm{~mm}$. \\
\hline Relación cemento/arena.. & $1: 3$ & $1: 3$ \\
\hline Consistencia del mortero... & seca & plástica \\
\hline Llenado de los moldes. . . & pilon & manual \\
\hline Forma de las probetas.... & cubos y 8 & prismas \\
\hline Resistencias minimas: & & \\
\hline Comprestión 3 días ...... & & $110 \mathrm{~kg} \cdot \int \mathrm{cm} .^{2}$ \\
\hline $7 \geqslant \ldots \ldots$ & $20 u \mathrm{~kg} \cdot / \mathrm{cm} \cdot{ }^{2}$ & $180 \mathrm{~kg} . / \mathrm{cm} .^{2}$ \\
\hline , $28 n \ldots \ldots \ldots$ & $300 \mathrm{~kg} \cdot / \mathrm{cm} .2$ & $275 \mathrm{~kg} \cdot / \mathrm{cm} .^{2}$ \\
\hline Tracción o flexion & & $\cdot$ \\
\hline $3 \operatorname{dias} . \ldots$. & & $25 \mathrm{~kg} / \mathrm{cm}^{2}$ \\
\hline$\Rightarrow \quad 7 » \ldots \ldots$ & $17 \mathrm{~kg} / \mathrm{ctn} .^{2}$ & $35 \mathrm{~kg} . / \mathrm{cm} . \mathrm{z}$ \\
\hline 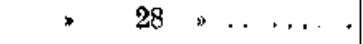 & $21 \mathrm{~kg} \cdot / \mathrm{cm} .^{2}$ & $50 \mathrm{~kg} . / \mathrm{cm} . .^{2}$ \\
\hline
\end{tabular}


Para el profano las Normas de 1956 vienen a ser menos exigentes, en lo que a resistencias a la compresión se refiere, que las Normas de hace veintisiete años. El hecho que a simple vista se nota, es que antes sc exigían $200 \mathrm{~kg} / \mathrm{cm}^{2}$ a los siete días y ahora bastan 180, observación que, para los ensayos a veintiocho días, se traduce en wn descenso de 300 a $275 \mathrm{~kg} / \mathrm{cm}^{2}$. Consecuencia inmediata de esta observación superficial es que la calidad de los cementos fabricados en 1956 es inferior a la de los cementos fa. bricados en 1930.

Afortumadamente, esta aparente objeción no hizo mella en el ánimo de los fabricantes portugueses. La construcción en époças recientes de grandes obras de ingeniería, como presas, puentes y aeropuertos, y el contacto permanente que se ha mantenido con técnicos extranjeros y con sus modos de hacer, tenía en muy bajo crédito las Normas de 1930. Cuando de una obra de mucha importancia se trataba, los Pliegos de Condiciones particulares ya estipulaban ensayos que se referían mejor a las Normas suizas, americanas o inglesas que a las Normas vigentes en el país. En muchos casos los ensayos se efectuaban por duplicado, siguiendo las Normas oficiales como base para el control, y de acuerdo con las Normas extranjeras para ver si el cemento producido o consumido estaba a la altura de sus congéneres del mercado exterior. Este control doble llegó a ser muy frecuente en las fábricas de cemento portuguesas.

Los ensayos sistemáticos a que yá nos hemos referido, sirvieron de intraducción muy adecuada para las nuevas Normas. Durante tres años se efectuaron ensayos dobles -según las N. P. 1930 y según las Normas en proyecto-, obteniéndose los siguientes resultados:
Ensayos de resistencia mecánica de fos cementos portugueses en 1955

Resultados obtenidos por el L.N.E.C.

\begin{tabular}{|c|c|c|c|c|c|c|}
\hline \multirow{2}{*}{$\begin{array}{c}\text { Compresión } \\
\mathrm{kg} / \mathrm{cm}^{2}\end{array}$} & \multicolumn{3}{|c|}{ N.P. 1930} & \multicolumn{3}{|c|}{ N. P. 1956} \\
\hline & 8 dias & 7 dias & 28.dias & $3 \mathrm{dizs}$ & 7 dias & 28 días \\
\hline Cemento A & 363 & 456 & 550 & 156 & 232 & 340 \\
\hline$y$ & 386 & 461 & 559 & 168 & 231 & 332 \\
\hline $\mathrm{C}$ & 398 & 510 & 626 & 146 & 218 & 326 \\
\hline D & 376 & 503 & 640 & 152 & 230 & 354 \\
\hline$\triangleright$ & 487 & 538 & 676 & 184 & 246 & 368 \\
\hline
\end{tabular}

\begin{tabular}{|c|c|c|c|c|c|c|}
\hline \multirow{2}{*}{$\begin{array}{c}\text { Flexión } \\
\text { o traceión } \\
\mathrm{kg} / \mathrm{cm}^{2}\end{array}$} & \multicolumn{3}{|c|}{ N.P. 1930} & \multicolumn{3}{|c|}{ N. P. 1956} \\
\hline & 3 días & 7 dias & Z8 dias & 8 djas & 7 dfas & 28 dias \\
\hline Cemento A & 28,8 & 29,2 & 34,8 & 33 & 43 & 57 \\
\hline$»$ & 30,2 & $3 i, 1$ & 36,1 & 36 & 44 & 57 \\
\hline$n$ & 29,2 & 31,3 & 35,8 & 34 & 43 & 56 \\
\hline " & 30,2 & 34,5 & 40,8 & 34 & 44 & 58 \\
\hline > & 25,8 & 30,2 & 37,9 & 35 & 44 & 61 \\
\hline
\end{tabular}

O seal, que las medias totales fueron:

\begin{tabular}{|c|c|c|c|c|}
\hline & $a=$ N.P. 1930 & $b=$ N.P. 1956 & $a f b$ & $b / a$ \\
\hline Compresión. & $499 \mathrm{~kg} / \mathrm{cm} \mathrm{c}^{\mathrm{e}}$ & $246 \mathrm{~kg} / \mathrm{cm} .^{2}$ & 2,03 & 0,49 \\
\hline Flex, o tracción & 32 & 45 & $0,7 \mathrm{l}$ & 1,41 \\
\hline
\end{tabular}

Lo cual nos dice que las resistencias a la compresión se redujeron, por término medio, a la mitad de lo que eran antes de la entrada en vigor de las N. P. 1956, mientras que las resistencias a la flexión resultaron ser, aproximadamente, 1,4 veces las resistencias a la tracción.

Hay que contar, sin embargo, con que los resultados obtenidos por tun laboratorio no suelen reproducirse en otros centros de ensayos. En Portugal se efectuaron ensayos de rotura de probetas faltricadas por un laboratorio oficiai, y rotas en 9 laboratorios diferentes. La influcncia a considerar era, principalmente, debida a las máquinas de ensayo de resistencias y, en menor grado, el 
"modus operandin de los varios ensayadores. Los resultados de estos ensayos se resumen así:

\section{Ensayos de conjunto de probetas fabricadas segun las Normas de 1956}

\begin{tabular}{|c|c|c|c|c|c|c|}
\hline \multirow[b]{2}{*}{ Ensayo } & \multirow[b]{2}{*}{ Edad } & \multirow{2}{*}{$\begin{array}{c}\text { Media } \\
\mathrm{kg} / \mathrm{cm}^{2}\end{array}$} & \multicolumn{2}{|c|}{$\underset{\text { medio }}{\text { Error cuadrático }}$} & \multirow{2}{*}{ 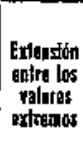 } & \multirow{2}{*}{$\begin{array}{l}\text { Medias } \\
\text { L.N.E.C } \\
\mathrm{kg} / \mathrm{cm}^{2}\end{array}$} \\
\hline & & & $\begin{array}{l}\text { Absolut. } \\
1 \mathrm{ikg} / \mathrm{cm}^{2}\end{array}$ & $\begin{array}{c}\text { Relativo } \\
\% \%\end{array}$ & & \\
\hline Compres. & $\mid \begin{array}{r}3 \text { días } \\
7 \\
28\end{array}$ & $\begin{array}{l}171 \\
262 \\
352\end{array}$ & $\begin{array}{l}35,8 \\
34,0 \\
46,6\end{array}$ & $\begin{array}{l}20,4 \\
12,8 \\
12,1\end{array}$ & $\begin{array}{r}110 \\
90 \\
70\end{array}$ & $\begin{array}{l}185 \\
255 \\
397\end{array}$ \\
\hline Flexión. & $\begin{array}{r}3 \\
7 \\
28\end{array}$ & $\begin{array}{l}39 \\
47 \\
66\end{array}$ & $\begin{array}{l}4,9 \\
4,3 \\
2,9\end{array}$ & $\begin{array}{r}12,3 \\
8,1 \\
4,5\end{array}$ & $\begin{array}{l}16 \\
15 \\
10\end{array}$ & $\begin{array}{l}39 \\
49 \\
65\end{array}$ \\
\hline
\end{tabular}

Cuando las probetas fueron preparadas por los laboratorios particulares, empleando arenas locales, las dispersiones, contra lo que era de presumir, no resultaron ser mayores, con lo que se denostró la influencia preponderante de la exactitud de la máquina o máquinas empleadas en las roturas de probetas.

La conclusión inmediata es caue los laboratorios de fábrica dếben equiparse con máquinas de ensayo de alta precisión y someterlas periódicamente a su verificación y afinación por parte competente.

Nos cupo en sterte trajajar con una máquina Amsler de 50 toneladas que, despuics de las comprobaciones oficiales debidas, dcmostró poseer una exactitud, definida por:

$$
100 \frac{M-F}{F} \leq 0,8 \%
$$

doncle:

$M=$ Lectura media de cinco determinaciones de $F$.

$\mathrm{F}=$ Fuerza exacta en kilogramos,
Con esta máquina efectuamos variados ensilyos de resistencia, por duplicado, siguiendo las Normas de 1930 y las de 1956. Los resultados obtenidos se expresan gráficamente en la figura 14. Vemos en ella que la ordenación de los puntos obtenidos se ajusta mejor a una función potencial que a tuna función lineal. I,a función potencial estudiada nos indica que la disminución de resistencias obtenidas por las nuevas N. P. 1956 perjudica más a las compresiones bajas, o sea, las tensiones de rotura a los tres dias, o a los cementos de escasa resistencia. Teóricamente, tın cemento con $800 \mathrm{~kg} / \mathrm{cm}^{2}$ de resistencia daría resultados parecidos, in. dependientemente de ta norma de ensayo.

Para los ensayos a flexión se ha utilizado la clásica balanza de Michaelis, con un dispositivo muy parecido al que se describe en las Normas suizas, que sirve para romper los prismas de mortero bajo un esfuerzo centrado entre dos apoyos. En la figura 15 se han referido los puntos obtenidos a otra función potencial. Carecemos de resistencias inferiores a $20 \mathrm{~kg} / \mathrm{cm}^{2}$, pero la extrapolación de 20 a cero nos indica que, en este caso, las resistencias a la flexión serían muy bajas y siempre menores que las resistenciass a la tracción.

Puede decirse, en conclusión, que los ensayos efectuados de acuerdo con las N. P. 1956 favorecen muy especialmente a los cementos portland de alta calidad, circunstancia por. la cual su introducción ha merecido muy escasos reparos por parte de los fabricantes portugueses.

Ein 10 que tocal a los ensayos de laborntorio, vamos a dar un esquema demostrativo de la conveniencia de ceñirnos a las nuevas N. P. 1956 : 


\begin{tabular}{|c|c|c|}
\hline Ensayos de resistenclas & N.P. 1990 & N. P. $195 B$ \\
\hline 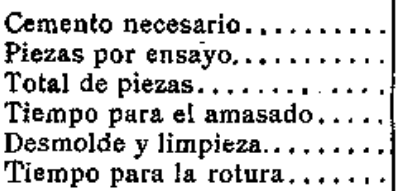 & $\begin{array}{c}8,000 \mathrm{~kg} . \\
6: \\
36: \\
4 \text { horas } \\
3 \quad \\
1 \mathrm{~h} .20 \mathrm{~min} .\end{array}$ & $\begin{array}{c}1,500 \mathrm{~kg} . \\
3 \\
9 \\
1 \text { hota } \\
30 \text { minutos } \\
45 \quad\end{array}$ \\
\hline
\end{tabular}

Por viltimo, destaquemos la importancia que tiene el esforzarnos en unificar las Normas de ensayo de los diferentes países y, en este aspecto, hay que consiguar que en Portugal se han seguido con bastante fidelidad las Recomendaciones de la R. I. L. E. M., que son, sin duda, las que gozan actualmente de mayor preferencia en los medios cien-

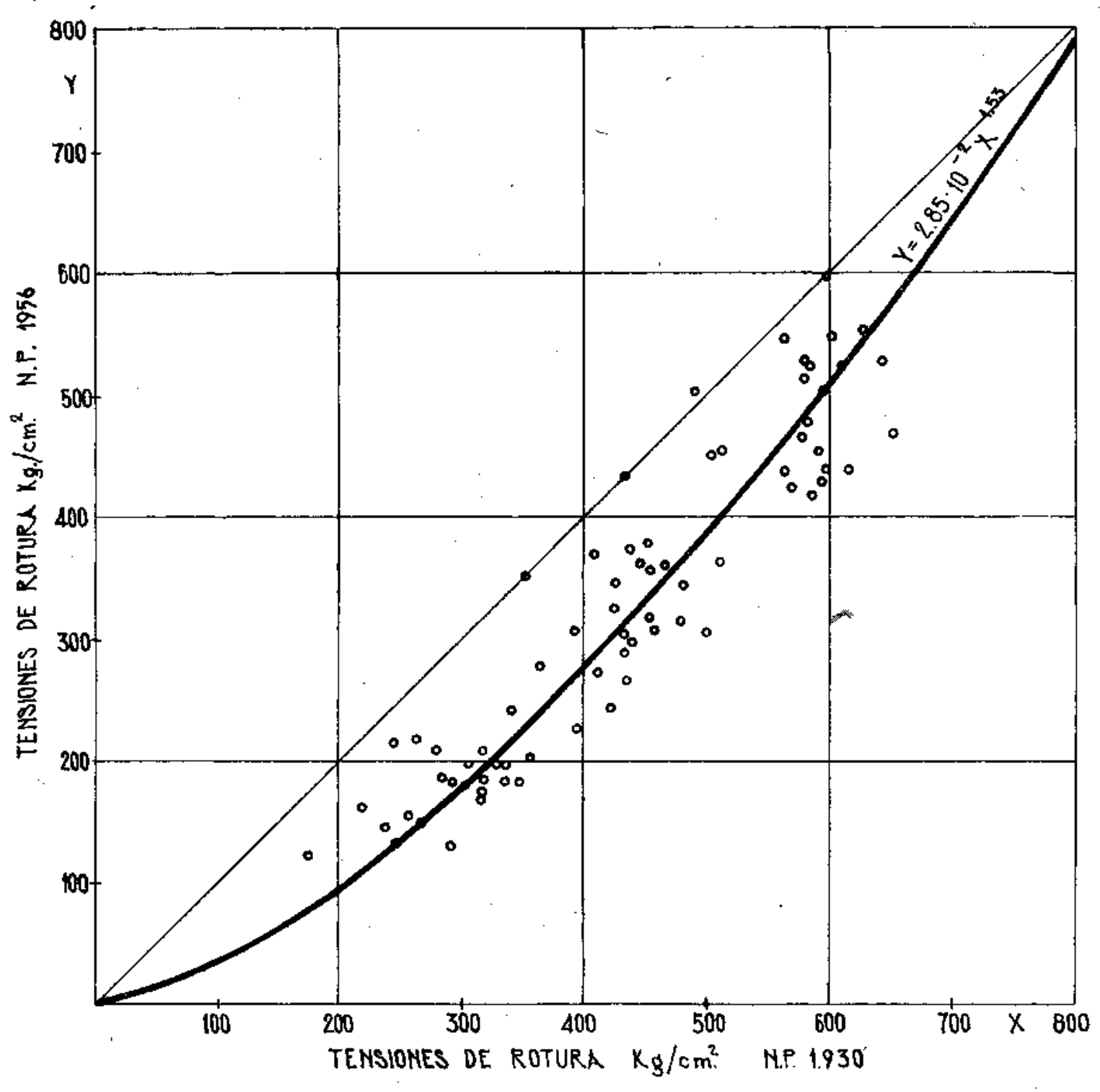

Fig 14 
tíficos de Europa. Sabemos que en España y en Francia se trabaja con interćs para introducir las Normas R. I. L. I.. M. No ig-
Connuniclad Británica y Rusia, con todos los pueblos de su esfera de influencia. Pese al apartamiento de estos tres grandes, estamos

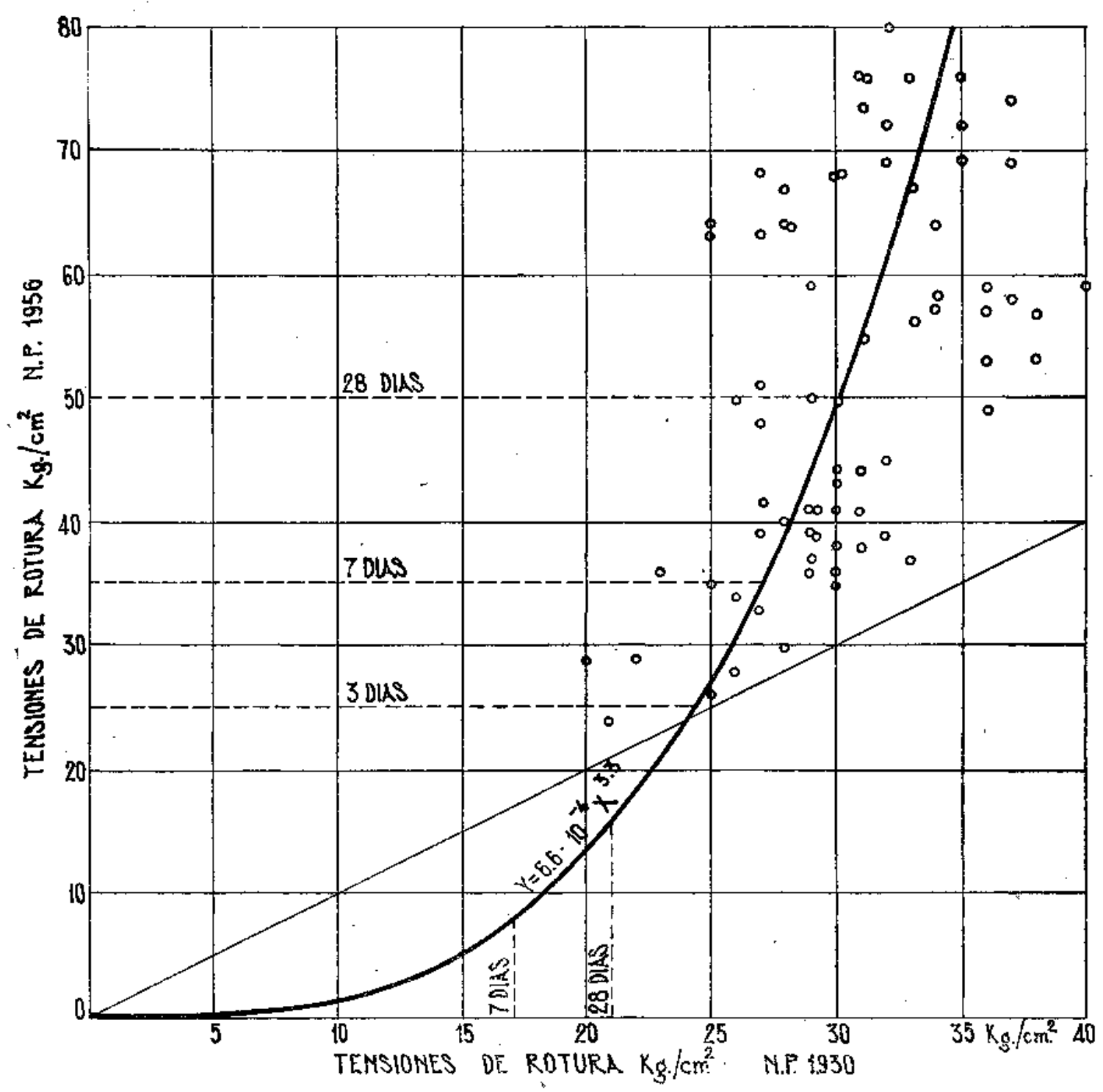

Fig. 15

noramos que algunos de los mayores productores de cemento del mundo están completamente apartados de la tendencia europea, especialmente los Estados Unidos y demás países americanos, Inglaterra y la. convencidos de que la Europa Occidental puede y debe dar un paso decisivo para la normalización internacional, y que los fabricantes de cemento no pueden permanecer al margen de este movimiento. 


\section{RES U M E N}

Los ensayos de calidad que suelen efectuarse en los laboratorios de las fábricas de cemento se basan en los «Pliegos de Condicionesn que para la recepción de aglomerantes hidráulicos cada país tiene promulgados.

Por otra parte, es una tendencia general en las fábricas la adopción de métodos de ensayo propios que sustituyen o complementan a los métodos normalizados. Cuando así sucede, es necesario averiguar el punto de coincidencia entre unos y otros métodos. En general, se observa una cierta di. vergencia de resultados cuando se comparan los ensayos efectuados por varios laboratorios.

En Portugal pudo establecerse la comparación de los resultados obtenidos por varios laboratorios, gracias a la ejecución de un vasto plan de «Ensayos Sistemáticos», elaborado y dirigido por el Laboratorio $\boldsymbol{N}_{\mathrm{a}}$ cional de Engenharia Civil (L. N. E. C.), con la colaboración económica y técrica de todas las fábricas de cemento portland del país.

Como consectuencia del desarrollo de este plan, apareció el nuevo "Caderno de Encargos para o Fornecimento e Recepçāo do Cimento "Portland" Normal», de 22 de no- viembre de 1950 , gue sustituye al anterior Pliego, de 28 de agosto de 1930 .

E1 nuevo Pliego presenta, entre otras novedades, la adaptación de los ensayos mecánicos a las Recomendaciones de la RILEM, $y$ en nuestro estudio se ha tratado de evidenciar la equivalencia de las tensiones de rotura, según los ensayos efectuados én un laboratorio fabril, siguiendo ambos métodos operatorios.

\section{$\triangle P E N D I C E$}

Cuadernos de Encargos y Nomas de Ensayos de Cementos de Portugal

1930, 28 de agosto.-Decreto núm. 18.782: "Caderno de Encargos para o Fornecimento e Recepção do Cimento "Portland» Normalm.

1932, 20 de febrero.-Decreto núm. 20.918: "Cláusulas Especiais para o Fornecimento e Recepção do Cimento "Portland" destinado a obras sujeitas a acção de águras saIinasy.

1943, 2 de septiembre.-Decreto núm. 25.948: "Regulamento do Betão Armado».

1946, 10 de octubre.-. "Caderno de Encargos provisorio para o Fornecimento e Recepção de Cimentos Especiais».

1956. 22 de noviembre.-Decreto número 40.870: "Caderno de Encargos para o Fornecimento e Recepção do Cimento "Portland" Normal». 